\title{
Article \\ A Novel Model for the RNase MRP-Induced Switch between the Formation of Different Forms of 5.8S rRNA
}

\author{
Xiao Li $^{1,2,+}$, Janice M. Zengel ${ }^{1}$ and Lasse Lindahl ${ }^{1, *(D)}$ \\ 1 Department of Biological Sciences, University of Maryland Baltimore County (UMBC), 1000 Hilltop Circle, \\ Baltimore, MD 21250, USA; xiao.li@abbott.com (X.L.); Janicezengel@gmail.com (J.M.Z.) \\ 2 Department of Biology, University of Rochester, Rochester, NY 14627, USA \\ * Correspondence: lindahl@umbc.edu \\ † Current address: Abbott Laboratories, San Diego, CA 92121, USA.
}

Citation: Li, X.; Zengel, J.M.; Lindahl, L. A Novel Model for the RNase MRP-Induced Switch between the Formation of Different Forms of 5.8S rRNA. Int. J. Mol. Sci. 2021, 22, 6690. https://doi.org/10.3390/ijms22136690

Academic Editor: Yves Henry

Received: 27 April 2021

Accepted: 17 June 2021

Published: 22 June 2021

Publisher's Note: MDPI stays neutral with regard to jurisdictional claims in published maps and institutional affiliations.

Copyright: (c) 2021 by the authors. Licensee MDPI, Basel, Switzerland. This article is an open access article distributed under the terms and conditions of the Creative Commons Attribution (CC BY) license (https:/ / creativecommons.org/licenses/by/ $4.0 /)$.

\begin{abstract}
Processing of the RNA polymerase I pre-rRNA transcript into the mature 18S, 5.8S, and 25S rRNAs requires removing the "spacer" sequences. The canonical pathway for the removal of the ITS1 spacer involves cleavages at the $3^{\prime}$ end of $18 \mathrm{~S}$ rRNA and at two sites inside ITS1. The process can generate either a long or a short 5.8S rRNA that differs in the number of ITS1 nucleotides retained at the $5.8 \mathrm{~S} 5^{\prime}$ end. Here we document a novel pathway to the long $5.8 \mathrm{~S}$, which bypasses cleavage within ITS1. Instead, the entire ITS1 is degraded from its $5^{\prime}$ end by exonuclease Xrn1. Mutations in RNase MRP increase the accumulation of long relative to short 5.8S rRNA. Traditionally this is attributed to a decreased rate of RNase MRP cleavage at its target in ITS1, called A3. However, results from this work show that the MRP-induced switch between long and short 5.8S rRNA formation occurs even when the A3 site is deleted. Based on this and our published data, we propose that the link between RNase MRP and 5.8S 5' end formation involves RNase MRP cleavage at unknown sites elsewhere in pre-rRNA or in RNA molecules other than pre-rRNA.
\end{abstract}

Keywords: ribosome biogenesis; rRNA processing; RNase MRP; long/short 5.8S rRNA

\section{Introduction}

Ribosome formation is the most resource-requiring process in both pro- and eukaryotes [1-3]. It involves complex pathways for regulated synthesis of rRNA and ribosomal proteins (r-proteins), and the assembly of these components into functional ribosomal subunits. The pathways differ between pro- and eukaryotes, but in eukaryotes the major steps are conserved from yeast to humans, although the complexity has evolved [4-6].

The progression of eukaryotic ribosome formation has been most intensively studied in Saccharomyces cerevisiae ("yeast") [7-9]. In this work, we focus on the processing of the yeast rRNA. Three of the four eukaryotic rRNA molecules are generated from a single precursor rRNA (pre-rRNA), polymerized by Pol I, which contains the sequences for 18S, 5.8S, and 25S rRNA separated by the internal transcribed spacers ITS1 and ITS2, and flanked by $5^{\prime}$ and $3^{\prime}$ external transcribed spacers (ETS) (Figure 1A). The pre-rRNA is processed by endo- and exonucleases to form the mature rRNAs (Figure 1B) concurrently with the assembly of the rRNA and 79 r-proteins into the two ribosomal subunits [9]. The rRNA processing can take place during transcription or after completed synthesis of the pre-rRNA transcript [10,11].

The canonical model for processing of the primary Pol I transcript begins with the Utp24 and Rnt1 endonucleases splitting the $5^{\prime}$ ETS and $3^{\prime}$ ETS, respectively, from the main portion of the pre-rRNA, generating the 32S intermediate (Figure 1B) [12-14]. Utp24 then cuts at the A2 site in ITS1, which separates the rRNA moieties destined for the $40 \mathrm{~S}$ or the $60 S$ ribosomal subunit $[12,14,15]$. ITS1 is further processed to generate the $5^{\prime}$ end of the $5.8 \mathrm{~S}$ rRNA and the $3^{\prime}$ end of $18 \mathrm{~S}$ rRNA (see below). The $3^{\prime}$ end of $5.8 \mathrm{~S}$ rRNA is generated 
by Las1 cleavage at the C2 site in ITS2 followed exonuclease cut-back by the exosome [16]; the downstream part of ITS2 is removed by exonucleases Rat1 and Xrn1 [17].

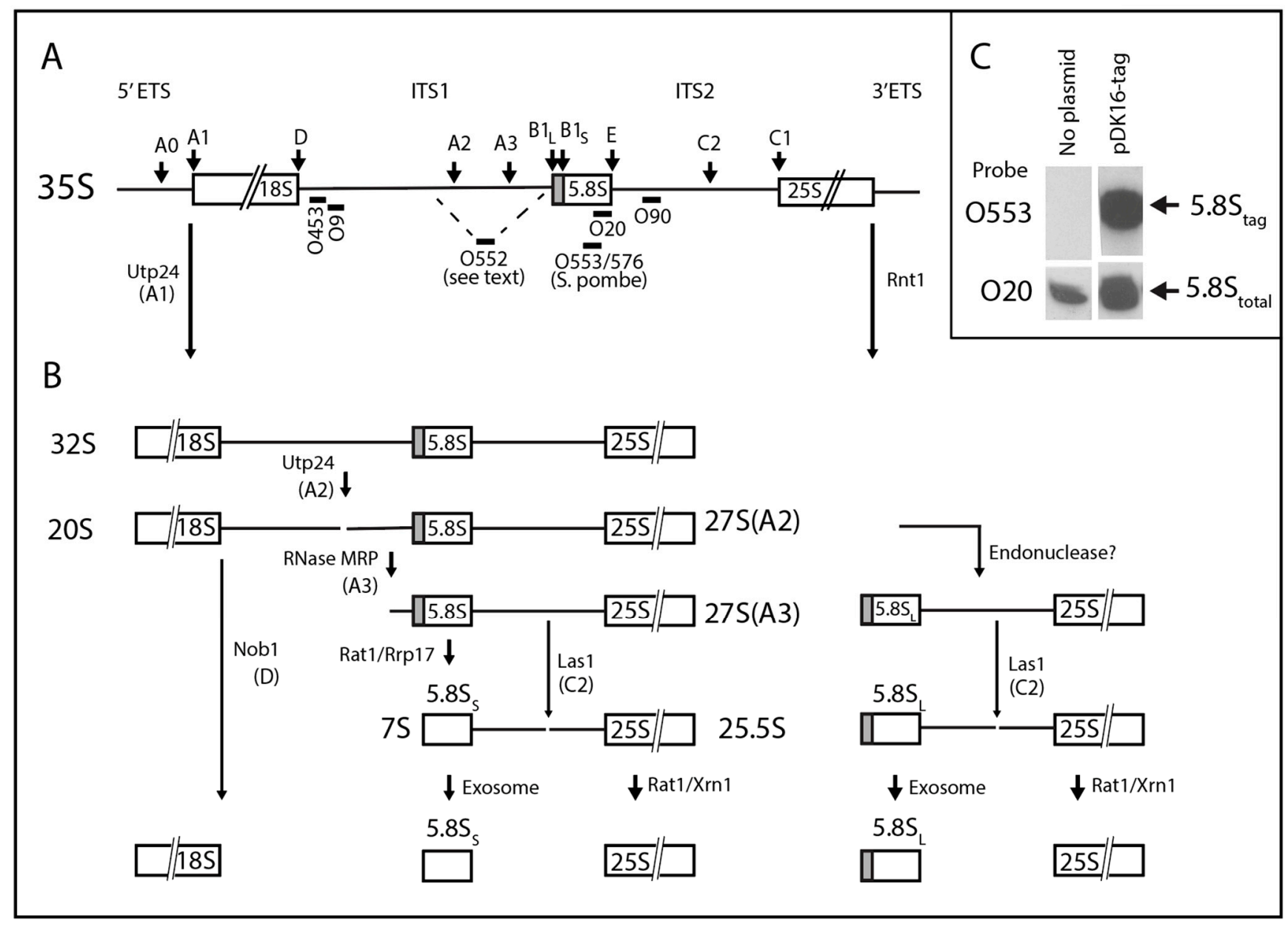

Figure 1. Canonical rRNA processing pathways. (A) Map of the yeast RNA polymerase I-transcribed rRNA transcription unit with processing sites (above map) and oligonucleotides used for probing northern blots (below map). See Table 1 for oligonucleotide sequences and positions of pre-rRNA to which they hybridize. (B) rRNA processing intermediates with names of relevant processing enzymes and their sites of action. Only relevant steps are shown. (C) Specificity of northern probe for tagged 5.8S rRNA. $\triangle r p a 12$ without plasmid or carrying pDK16-tag wildtype was grown at $25^{\circ}$ and shifted to $37^{\circ}$ for $6 \mathrm{~h}$. Total RNA was analyzed by northern analysis using the O553 probe (complementary to the S. pombe tag in 5.8S rRNA on pDK16-tag) or the O20 probe (complementary to the 25 nucleotides at the $3^{\prime}$ end of 5.8S rRNA).

There are two pathways that generate the $5^{\prime}$ end of the 5.8S. In the major pathway, the ribozyme RNase MRP cuts ITS1 at the A3 site, followed by trimming of the resulting $5^{\prime}$ end by a combination of Rat 1 and Rrp 17 exonucleases to form the $5^{\prime}$ end of the "short" $5.8 \mathrm{~S}$ rRNA $\left(5.8 \mathrm{~S}_{\mathrm{S}}\right)$ (Figures 1 and 2) [18-24]. The other pathway ostensibly involves an unknown endonuclease that directly generates the $5^{\prime}$ end of the "long" $5.8 \mathrm{~S}$ rRNA $\left(5.8 \mathrm{~S}_{\mathrm{L}}\right)$, which is 7 nucleotides longer at the $5^{\prime}$ end than $5.8 \mathrm{~S}_{\mathrm{S}}$ [25]. Mutations in the RNA or protein subunits of RNase MRP favor the accumulation of $5.8 \mathrm{~S}_{\mathrm{L}}$, increasing the fraction of the total $5.8 \mathrm{~S}$ rRNA constituted by $5.8 \mathrm{~S}_{\mathrm{L}}$ ("L-fraction") $[23,26-31]$. It is generally believed that this is caused by a decreased rate of RNase MRP cleavage at A3, which in turn reduces the number of A3 5' ends available for attack by Rat1 and Rrp17.

Here, we made two discoveries that implicate changes to the current model for $5.8 \mathrm{~S}$ processing. First, processing of pre-rRNA carrying a deletion that removes both A2 and A3 sites was degraded by the exonuclease Xrn1 beginning from the $5^{\prime}$ end generated by D-cleavage and ending at the $5^{\prime}$ end of $5.8 \mathrm{~S}_{\mathrm{L}}$. This extended our previous observation that 
after inactivation of RNase MRP, processing of wildtype rRNA exclusively generates $5.8 \mathrm{~S}_{\mathrm{L}}$ and that this process also requires Xrn1 [30]. Hence, we proposed that the Xrn1-dependent pathway to $5.8 \mathrm{~S}_{\mathrm{L}}$ also occurred during processing of wildtype pre-rRNA. Second, we found that the L-fraction increases in an RNase MRP mutant, even if the A3 site in the pre-rRNA is deleted, indicating that the RNase MRP effect on the L-fraction is not the result of decreased A3 cleavage. Consequently, we suggest that RNase MRP modulation of the level of $5.8 \mathrm{~S}_{\mathrm{L}}$ is indirect.

Table 1. Sequence of oligonucleotides used.

\begin{tabular}{ccc}
\hline Oligo & Sequence $\left(\mathbf{5}^{\prime} \rightarrow \mathbf{3}^{\prime}\right)$ & Complementary to \\
\hline O9 & GCT CTT GCC AAA ACA AAA AAA TCC A & ITS1 24-53 \\
\hline O20 & AAA TGA CGC TCA AAC AGG CAT GCC C & 5.8S $\mathbf{3}^{\prime}$ end \\
\hline O90 & GTA TCA CTC ACT ACC AAA CAG AAT G & ITS2 11-35 \\
\hline O453 & AAC AAA AAA ATC CAT TTT CAA & ITS1 15-25 \\
\hline O552 & CCA GTT ACG CGT TTT AAT TG & Spanning $\Delta 2$ deletion, see text \\
\hline O553 & ATG CCT TTG GTA GAA CCC AAA GGC & $\begin{array}{c}\text { S. pombe hairpin inserted in } \\
\text { S. cerevisiae } 5.8 S\end{array}$ \\
\hline O576 & ATG CCT TTG GTA GAA CCC & $\begin{array}{c}\text { S. pombe hairpin inserted in } \\
\text { S. cerevisiae } 5.8 S\end{array}$ \\
\hline
\end{tabular}

\section{Results}

\subsection{System for Genetic Analysis}

The S. cerevisiae genome has 100-200 tandem copies of the 18S-5.8S-25S rRNA transcription unit that is transcribed by RNA Pol I [32]. The large number of rRNA genes makes traditional genetic manipulation difficult and we therefore used strains in which Pol I is inactivated either permanently $(\Delta r p a 135)$ or conditionally at $37^{\circ}(\Delta r p a 12)[33,34]$ (Table 2). Both strains harbor an 18S-5.8S-25S rRNA transcription unit on the high-copy plasmid pDK16 that is transcribed by RNA polymerase II (Pol II) from the $\mathrm{Cu}^{2+}$ induced CUP1 promoter [35]. Previous studies showed that pre-rRNA transcripts produced by Pol II are processed through the same steps as the natural Pol I transcripts $[33,35]$.

Table 2. Strains and plasmids.

\begin{tabular}{|c|c|c|}
\hline Name & Genotype & References \\
\hline $\begin{array}{l}\Delta r p a 12 \text { alias } \\
\text { NOY504 }\end{array}$ & $\begin{array}{l}\text { MATa rm4 (rpa12)::LEU2 ade2-101 ura3-1 trp1-1 } \\
\text { leu2-3,112 his3-101 can1-100 }\end{array}$ & {$[34]$} \\
\hline $\begin{array}{l}\Delta r p a 135 \text { alias } \\
\text { NOY408-la }\end{array}$ & $\begin{array}{l}\text { MATa rpa135::LEU2 ade2-1 ura3-1 his3-10 1trp1-1 } \\
\text { leu2-112 can1-100/pNOY102 }\end{array}$ & [33] \\
\hline$\Delta r p a 135 / \mathrm{pDK} 16$ & $\begin{array}{l}\text { MATa rpa135::LEU2 ade2-l ura3-l his3-ll trpl-1 } \\
\text { leu2-3,112 can1-100/pDK16 }\end{array}$ & This study \\
\hline YLL53 & MATa ade2-101 his3 $\Delta 200$ ura3-52 tyr1 RRP2 & [23] \\
\hline YLL54 & MATa ade2-101 his3 $\Delta 200$ ura3-52, lys2, rrp2-2 & [23] \\
\hline pDK16 & $\begin{array}{l}\text { YEplac112 carrying the rRNA transcription unit } \\
\text { expressed from the CUP1 promoter }\end{array}$ & {$[35]$} \\
\hline pDK16-tag & pDK16 with tagged 5,8S gene (see text) & This study \\
\hline
\end{tabular}

To discriminate between the $5.8 \mathrm{~S}$ rRNA transcribed from the plasmid-borne Pol IIdriven rRNA genes and the chromosomal Pol I rRNA genes, we tagged the 5.8S rRNA derived from pDK16 by replacing the DNA sequence corresponding to a hairpin formed by nucleotides $124-147$ of the $5.8 \mathrm{~S}$ rRNA with the DNA sequence that generates the same 
hairpin in Schizosaccharomyces pombe (Sp) 5.8S rRNA, albeit with a different nucleotide sequence. The modified 5.8S rRNA transcribed from this plasmid, called pDK16-tag, was detected on northern blots by probing with an oligonucleotide (O553 or O576) that is complementary to the $S$. pombe sequence (Table 1). Total 5.8S rRNA transcribed from both wildtype and tagged genes was visualized on northern blots by a probe, $\mathrm{O} 20$, which is complementary to the 25 nucleotides at the $3^{\prime}$ end of $5.8 \mathrm{~S}$ rRNA and thus present in both wildtype and Sp-tagged 5.8S rRNA (Figure 1C).

\subsection{Effects of ITS1 Deletions on $5.8 S$ rRNA Processing}

Previous experiments have shown that the canonical A2 and A3 cleavage sites in ITS1 are dispensable for formation of mature rRNA [21,35]. To determine if other regions in ITS1 are necessary for 5.8S rRNA formation, we generated several ITS1 deletions in the rRNA transcript on pDK16-tag (Figure 2A). The deletion plasmids were transformed into the temperature-sensitive strain $\triangle r p a 12$ to test if the ITS1-rRNA deletion genes can support growth at the non-permissive temperature for RNA Pol I in the presence of $\mathrm{Cu}^{2+}$, the inducer of the CUP1 promoter driving transcription of the plasmid-borne rRNA transcription unit (Figure S1, see Materials and Methods for specifics). Somewhat surprisingly, only one deletion $(\Delta 4)$, removing 82 nucleotides in the upstream part of ITS1, was lethal at $37^{\circ}$, and a shorter deletion within the same region of ITS1 $(\Delta 7)$ resulted in severely impeded growth (Figure S1A). All the remaining deletion plasmids supported growth at $37^{\circ}$ (Figure $\mathrm{S} 1$ and not shown). To confirm the ability of the longest ITS1 deletion $(\Delta 2)$ to provide functional rRNA, we transformed it into the $\Delta r p a 135$ mutant and found that it supports growth in the presence, but not in the absence, of $\mathrm{Cu}^{2+}$ (Figure S1B, see Materials and Methods for specifics).

We next asked if the viable deletions affect the relative accumulation of the long $\left(5.8 \mathrm{~S}_{\mathrm{L}}\right)$ and short $\left(5.8 \mathrm{~S}_{\mathrm{S}}\right)$ rRNAs. For these experiments, we chose a derivative of $\Delta$ rpa12 in which we had deleted the XRN1 gene, because internal ITS1 fragments are stabilized in the absence of the Xrn1 exonuclease [36]. Cultures of this host carrying pDK16-tag or its deletion derivatives were grown at $25^{\circ}$ and shifted to $37^{\circ}$ for $6 \mathrm{~h}$. Total RNA was analyzed by acrylamide gel electrophoresis and northern blot hybridization, using the oligonucleotide probe $\mathrm{O} 553$ (complementary to the 5.8S Sp tag). As seen in Figure 3 the fraction of $5.8 \mathrm{~S}$ rRNA constituted by the long form (L-fraction) increased very noticeably when rRNA was processed from several of the mutant plasmids. Moreover, bands of relatively low mobility appeared in some lanes, but there is not a one-to-one correlation between the increased L-fraction and the appearance of the slow-moving bands (Figure S2). To determine if the $5^{\prime}$ ends of the two types of $5.8 \mathrm{~S}$ match those resulting from processing of wildtype pre-rRNA, we expressed pDK16-tag with and without the $\Delta 2$ deletion in $\Delta$ rpa135 and used total RNA for primer extension of O20 that is complementary to the $3^{\prime}$ end of the mature 5.8S (Figure 4). The results show that positions of the $5^{\prime}$ ends of both the short and long $5.8 \mathrm{~S}$ rRNA match the $5^{\prime}$ ends observed when rRNA is expressed from wildtype chromosomal genes, i.e., the $5^{\prime}$ end of $5.8 \mathrm{~S}_{\mathrm{L}}$ retains 7 nucleotides more from the ITS than does $5.8 \mathrm{~S}_{\mathrm{S}}[31,37]$. 

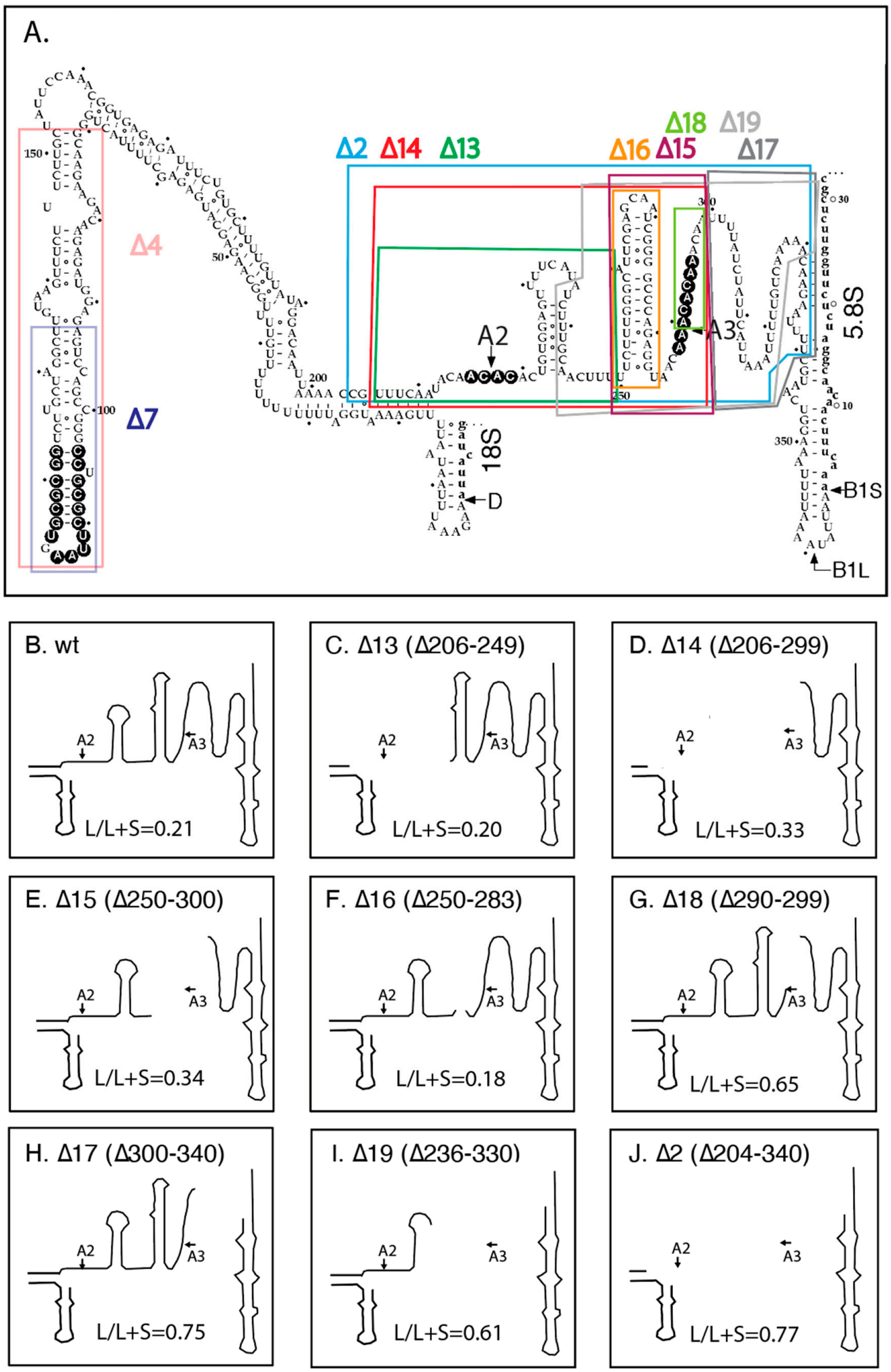

Figure 2. Deletion mutations in ITS1. (A) Secondary structure of ITS1 in S. cerevisiae proposed by van Nues at al. [38]. Deletions are shown by color-coded frames around the deleted nucleotides. Phylogenetically conserved nucleotides among a set of Saccharomycetales are shown in reverse contrast; for specifics see [36]. (B-J) Schematics of the ITS1 secondary structure in which the deleted parts in each mutant are blocked out. The total $5.8 \mathrm{~S}$ rRNA constituted by $5.8 \mathrm{~S}_{\mathrm{L}}$ ("L-fraction") was determined from northern blots loaded with RNA extracted from cells carrying each of the deletion plasmids. The numbers are the average of the measurements from $25^{\circ}$ and $37^{\circ}$ in $\triangle r p a 12 \Delta x r n 1$ and YLL53 (RRP2); the latter strain is not deleted for XRN1. 


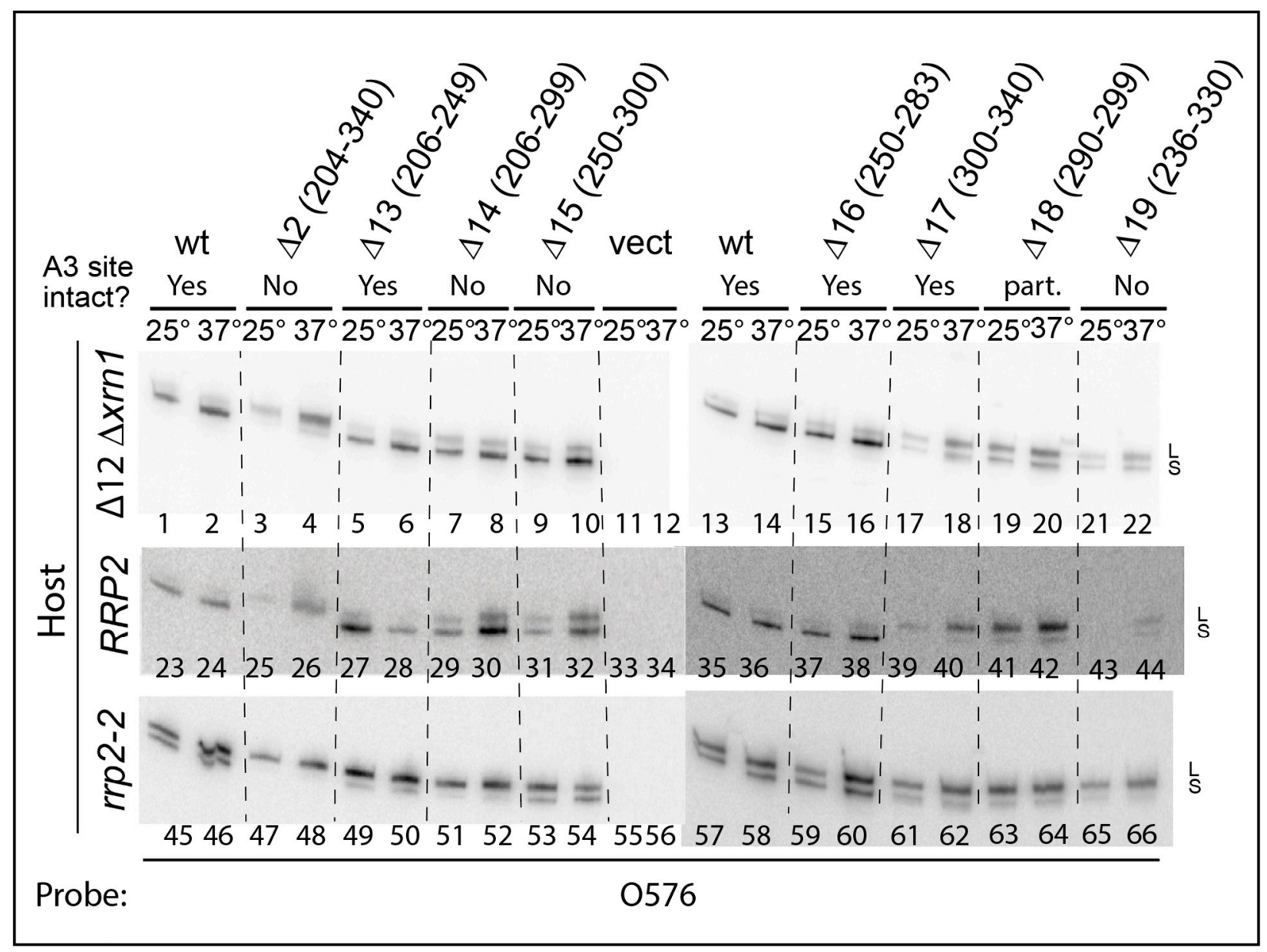

Figure 3. Northern analysis of RNA extracted from $\triangle r p a 12 \triangle x r n 1$ (top), $R R P 2$ (middle), and rrp2-2 (bottom) each carrying pDK16-tag or one of its ITS1 deletion derivatives. Total rRNA was fractionated by electrophoresis on acrylamide gels and probed with O576 on northern blots. See Figures S2 and S3 for uncropped autoradiograms.

We then calculated the ratio between the long $\left(5.8 \mathrm{~S}_{\mathrm{L}}\right)$ and short $\left(5.8 \mathrm{~S}_{\mathrm{S}}\right) 5.8 \mathrm{~S}$ rRNA (L-fraction) produced from each of the deletion pre-rRNAs. Since there was no difference between the results between rRNA extracted from cells growing at $25^{\circ}$ or shifted to $37^{\circ}$ (Figure S4), we merged results from the two sets of samples. (It was expected that the Lfraction would be very similar at the two temperatures, even though the rRNA processing pattern is changed by $4-6 \mathrm{~h}$ after the temperature shift due to inactivation of the $\Delta r p a 12$ PolI (see below). This is because processing intermediates turn over relatively quickly (in wildtype the processing of pre-rRNA takes about $10 \mathrm{~min}$ ), while the pool of the stable $5.8 \mathrm{~S}$ end products only changes with cell growth.). 


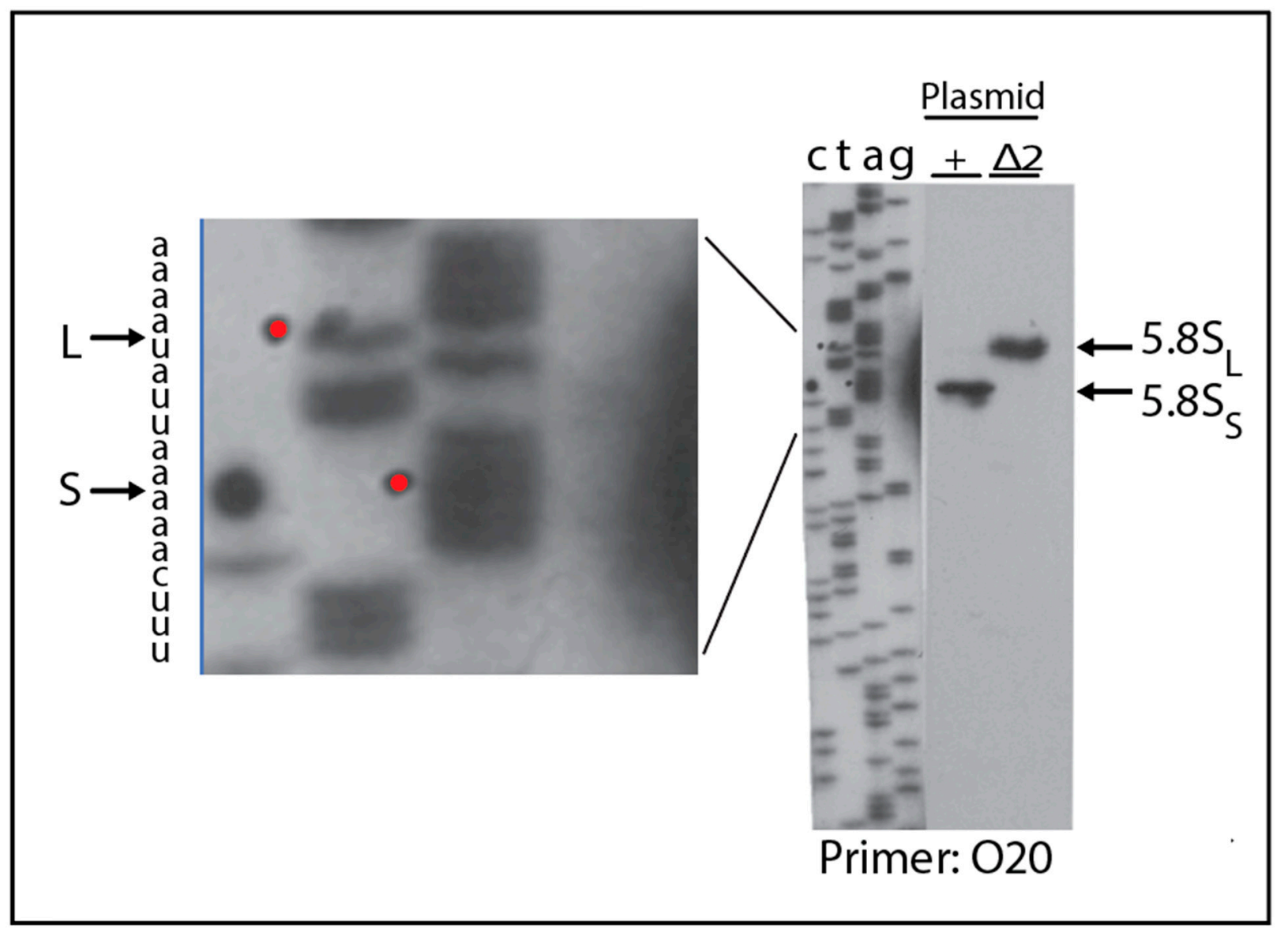

Figure 4. Mapping of $5^{\prime}$ ends of 5.8S rRNA processed from $\Delta 2$ and wildtype rRNA genes carried on plasmid pDK16. The host strain $\triangle$ rpa135 carrying wildtype pDK16 or pDK16 2 was grown in steady state at $30^{\circ}$. Total RNA was isolated and used for extension of primer O20. Di-deoxy sequencing ladders generated by extension of the O20 primer on the pDK16 DNA are shown as markers. Red dots in the sequence lanes indicate the bands that line up with the primer extension products. Note that the gel was loaded using a "shark-tooth comb", meaning that there is minimal space between the slots. The primer extension products from the $\mathrm{pDK} 16$ and pDK16 $\Delta 2$ were each loaded twice in neighboring lanes, but since the lanes are close, the bands of the duplicate loadings virtually merged into a single double-width band. Furthermore, a few irrelevant lanes between the sequence ladder and the primer extension products were excised from the image.

For wildtype ITS1, the L-fraction was 0.21 , i.e., the cells accumulated about 4 -fold more $5.8 \mathrm{~S}_{\mathrm{S}}$ than $5.8 \mathrm{~S}_{\mathrm{L}}$, consistent with the L-fraction in $5.8 \mathrm{~S}$ rRNA transcribed from chromosomal genes (Figure 5A; Table S1) [31,39]. Deletions removing the A2 site $(\Delta 13)$, the A2 and A3 sites together $(\Delta 14)$, the A3 site by itself $(\Delta 15)$, or a proposed hairpin upstream of the A3 site $(\Delta 16)$ all have no or modest $(\leq 1.5$-fold) effects on the L-fraction (Figure 5A; Table S1). However, a 10-nucleotide deletion immediately downstream of the A3 cleavage site $(\Delta 18)$ increased the L-fraction more than 2-fold. Importantly, a deletion that leaves the A2 and A3 sites intact but removes 41 nucleotides downstream of the A3 region $(\Delta 17)$ increases the L-fraction about 3-fold, showing that deletions in the distal end of ITS1 have stronger effects than the loss of the A3 site. This idea is supported by the increased L-fraction in $\Delta 2$ and $\Delta 19$, both of which lack portions of the region downstream of A3. Although these deletions also remove one or both of the A2 and A3 sites, comparison with the other deletions lacking the nucleolytic sites rule out that the presence or absence of A2 and A3 is of major importance for the balance between the short and long 5.8S rRNA. The salient features of the ITS1 deletions expressed in $\Delta r p a 12 \Delta x r n 1$ and other strains used for the following experiments are summarized in Table 3. 

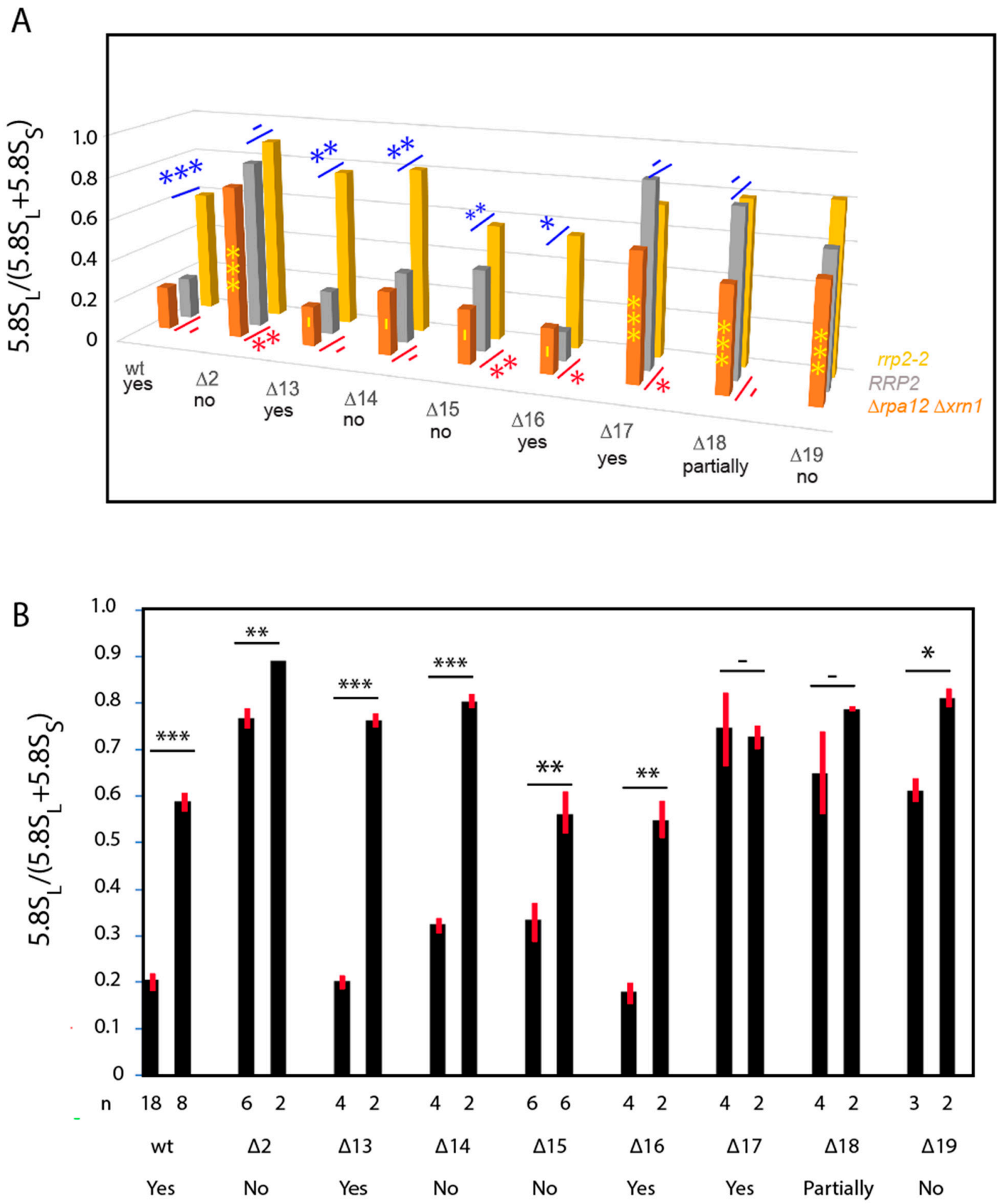

Figure 5. Bands in the northern blots shown in Figure 3 were quantified and the fraction of total 5.8S rRNA constituted by $5.8 \mathrm{~S}_{\mathrm{L}}$ was calculated. Data for $25^{\circ}$ and $37^{\circ}$ (Figure S4) were pooled for each strain (see text). (A) Data were plotted in a 3D format. Front row: $\triangle r p a 12 \Delta x r n 1$; middle row: RRP2 (YLL53); back row: rrp2-2 (YLL54). The results for different strains were compared by a Student's $t$-test. Yellow symbols: $\triangle r p a 12 \Delta x r n 1$ containing pDK16-tag deletion plasmids compared to $\Delta r p a 12 \Delta x r n 1$ with pDK16-tag (no ITS1 deletion); red symbols: comparing $\triangle r p a 12 \Delta x r n 1$ and $R R P 2$ harboring the same plasmid; blue symbols: comparing $R R P 2$ and rrp2-2 harboring the same plasmid. (B) Results from $\triangle r p a 12 \Delta x r n 1$ and $R R P 2$ carrying a given plasmid were averaged (left bar for each plasmid). Results for rrp2-2 are shown in the right bar for each plasmid. Standard deviations are shown by the red lines at the top of each bar (the standard deviation for $\Delta 2$ in the $r r p 2-2$ strain was 0 ). Note that the rrp2-2 strain grows at $25^{\circ}$, not at $37^{\circ}$, yet displays a similarly mutant RNA phenotype at both temperatures [31]. ${ }^{* * *} p<10^{-3} ;{ }^{* *} p<10^{-2} ;{ }^{*} p \leq 5 \times 10^{-2} ;-p>5 \times 10^{-2}$. 
Table 3. Summary of characteristics of ITS1 deletions.

\begin{tabular}{|c|c|c|c|c|c|c|c|c|c|c|}
\hline \multirow[b]{2}{*}{ Mutant } & \multirow[b]{2}{*}{ A2 } & \multirow[b]{2}{*}{ A3 } & \multirow[b]{2}{*}{ 283-289 } & \multicolumn{2}{|c|}{ ITS1 Nucleotides } & \multirow[b]{2}{*}{$331-340$} & \multicolumn{2}{|c|}{ L-Fraction } & \multirow[b]{2}{*}{$\begin{array}{l}\text { HI mw interm in } \\
\Delta r p a 12 \Delta x r n 1\end{array}$} & \multirow[b]{2}{*}{$\begin{array}{c}R R P 2 \\
\text { sensitivity }\end{array}$} \\
\hline & & & & 290-299 & $300-330$ & & $\begin{array}{c}\Delta r p a 12 \\
\Delta x r n 1\end{array}$ & $\begin{array}{c}R R P 2 \\
\text { (YLL53) }\end{array}$ & & \\
\hline wt & yes & yes & $\mathrm{P}$ & $\mathrm{P}$ & $\mathrm{P}$ & $\mathrm{P}$ & 0.21 & 0.20 & - & + \\
\hline$\Delta 13$ & no & yes & $\mathrm{P}$ & $\mathrm{P}$ & $\mathrm{P}$ & $\mathrm{P}$ & 0.19 & 0.21 & - & + \\
\hline$\Delta 14$ & no & no & A & A & $\mathrm{P}$ & $\mathrm{P}$ & 0.31 & 0.34 & - & + \\
\hline$\Delta 15$ & yes & no & A & A & $\mathrm{P}$ & $\mathrm{P}$ & 0.26 & 0.40 & - & + \\
\hline$\Delta 16$ & yes & yes & $\mathrm{P}$ & $\mathrm{P}$ & $\mathrm{P}$ & $\mathrm{P}$ & 0.22 & 0.14 & - & + \\
\hline$\Delta 17$ & yes & yes & $\mathrm{P}$ & $\mathrm{P}$ & A & A & 0.61 & 0.88 & + & - \\
\hline$\Delta 18$ & yes & half & $\mathrm{P}$ & A & $\mathrm{P}$ & $\mathrm{P}$ & 0.50 & 0.80 & + & - \\
\hline$\Delta 19$ & yes & no & $\mathrm{A}$ & $\mathrm{A}$ & $\mathrm{A}$ & $\mathrm{P}$ & 0.56 & 0.64 & - & nd \\
\hline$\Delta 2$ & no & no & A & A & A & A & 0.74 & 0.82 & + & - \\
\hline
\end{tabular}

Columns 2 and 3: Yes/no indicates whether the A2 and/or A3 processing sites are present or not in the mutant rRNA gene. "Half " indicates that only the upstream part of the processing site is present. Column 4 indicates whether the indicated range of ITS1 nucleotides are present $(\mathrm{P})$ or absent $(\mathrm{A})$ in each mutant. Column 5 shows the L-fraction $\left(5.8 \mathrm{~S}_{\mathrm{L}} /\left(5.8 \mathrm{~S}_{\mathrm{S}}+5.8 \mathrm{~S}_{\mathrm{L}}\right)\right.$ in the indicated strain. Column 6 indicates whether or not high molecular weight intermediates accumulate during ITS1 processing in each mutant (+: high mw intermediates accumulate; - : high mw intermediates do not accumulate). Column 7 indicates whether the L-fraction is significantly increased in the RRP2 strain versus the $\operatorname{rrp} 2-2$ mutant strain).

\section{3. pre-rRNA Processing Is Altered by an RNase MRP Mutation Even When the ITS1 A3 Site} Is Deleted

The 5.8S L-fraction increases in RNase MRP mutants [22,23,26-31]. This increase has been attributed to a reduced rate of A3 cleavage with an ensuing decrease in the number of A $35^{\prime}$ ends available for attack by Rat $1 / \operatorname{Rrp} 17$ to generate $5.8 \mathrm{~S}_{\mathrm{S}}$. If this explanation is true, then 5.8S rRNA formation in mutants lacking the A3 site should not be affected by RNase MRP mutations. To examine this, we transformed plasmid pDK16-tag and its deletion derivatives into two isogenic strains that either contain the wildtype gene for the RNase MRP RNA subunit (RRP2 alias NME1) or its temperature-sensitive sibling, rrp2-2, with a single-base substitution in the enzyme's RNA component (Table 2) [23]. Both of these strains have a wildtype XRN1 gene. Note, however, that even though the mutant grows at $25^{\circ}$ and not at $37^{\circ}$, there is little difference in the relative abundance of long and short $5.8 \mathrm{~S}$ rRNA at the two temperatures [31].

Total RNA from these strains was analyzed by northern blots for $5.8 \mathrm{~S}_{\mathrm{S}}$ and $5.8 \mathrm{~S}_{\mathrm{L}}$ derived from the Sp-tagged plasmids (Figure 3 middle and bottom panel). The L-fractions for RNA derived from the ITS1 deletion genes in the RRP2 strain differed little from the corresponding data measure in the $\Delta r p a 12 \Delta x r n 1$ background (Figure 5A; Table S1). An average of the results in the two strains are given in Figure $5 \mathrm{~B}$ and Table S1. However, the low-mobility bands seen in $\triangle r p a 12 \Delta x r n 1$ were not seen in the RRP2 strain, suggesting that they are due to the lack of Xrn1 activity (Figure S3).

As expected, the L-fraction of $5.8 \mathrm{~S}$ rRNA synthesized from the pDK16-tag plasmid without an ITS1 deletion is increased in the rrp2-2 mutant relative to the RRP2 parent strain (Figure 3, compare lanes 23-24 and 35-36 with lanes 45-46 and 57-58, respectively; quantified in Figure 5 and Table S1). The L-fraction is also increased in rrp2-2 harboring pDK16-tag $\Delta 13$ and $\Delta 16$ (Figure 3, compare lanes $27-28$ and 37-38 with lanes 49-50 and 59-60, respectively); both of these deletions leave the A3 site intact. Remarkably, the rrp2-2 mutation also changes the relative amount of $5.8 \mathrm{~S}_{\mathrm{L}}$ in mutants $\Delta 14$ and $\Delta 15$ (Figure 3, compare lanes 29-30 and 31-32 with lanes 51-52 and 53-54, respectively; quantified in Figure 5 and Table S1), even though A3 is deleted in these mutants. In contrast, the RNase MRP mutation has little effect on the L-fraction in mutants $\Delta 2, \Delta 17$ and $\Delta 18$, in which the L-fraction is already increased in the RRP2 wildtype background due to the 
deletions (Figure 5, compare lanes 25-26, 39-40, and 41-42 with lanes 47-48, 61-62, and 63-64, respectively).

\subsection{A Pathway to 5.8S rRNA That Bypasses the Canonical A2 and A3 Cleavage Sites in ITS1}

The accumulation of $5.8 \mathrm{~S}$ rRNA resulting from processing of the $\Delta 2$ and $\Delta 14$ mutants (Figures 2-5) shows that the canonical path to 5.8S rRNA via cleavage at A2 and/or A3 can be bypassed. To learn more about the bypass pathway(s), we first asked if the mutant pre-rRNAs are cleaved accurately at the D site at the $3^{\prime}$ end of mature $18 \mathrm{~S}$ rRNA. Total RNA from $\Delta$ rpa 12 cells harboring the pDK16-tag plasmid or the $\Delta 2, \Delta 13, \Delta 14$, and $\Delta 15$ deletion derivatives was prepared $6 \mathrm{~h}$ after a shift from $25^{\circ}$ to $37^{\circ}$, at which time wildtype processing intermediates derived from residual transcription of the chromosomal rRNA genes are no longer visible (see below). Total RNA was used as template for extension of oligonucleotide O9, which hybridizes to ITS1 24-53 nucleotides downstream of the D site (Figure $1 \mathrm{~A}$ and Table 1). RNA from the wildtype and the $\Delta 2, \Delta 13$, and $\Delta 14$ strains generated bands matching the $5^{\prime}$ end of ITS1, adjacent to the $3^{\prime}$ end of mature $18 \mathrm{~S}$ rRNA (Figure 6, lanes 2-5). Since both the A2 and A3 sites are deleted from $\Delta 2$ and $\Delta 14$, this demonstrates that accurate $\mathrm{D}$ cleavage does not depend on prior cleavage at $\mathrm{A} 2$ or $\mathrm{A} 3$. Interestingly, in mutant $\Delta 15$ the band corresponding to cleavage at $\mathrm{D}$ is absent; instead, there is a band corresponding to ectopic cleavage about 10 nucleotides downstream of the proper D site (Figure 6, lane 6, “D- 10"). A secondary band at "D- 10" is also seen in $\Delta 13$ (Figure 6, lane 4). It is interesting to note that the in vitro incubation of purified Nob1, the enzyme that cleaves the D-site (Figure 1B), with a short RNA substrate modeling 24 nucleotides around the 18S-ITS1 boundary region, also results in cutting at the precise D-site with a secondary target site about 10 nucleotides downstream of the D-site [40], supporting the idea that the D-site target of Nob1 is defined in the local region around the D-site.

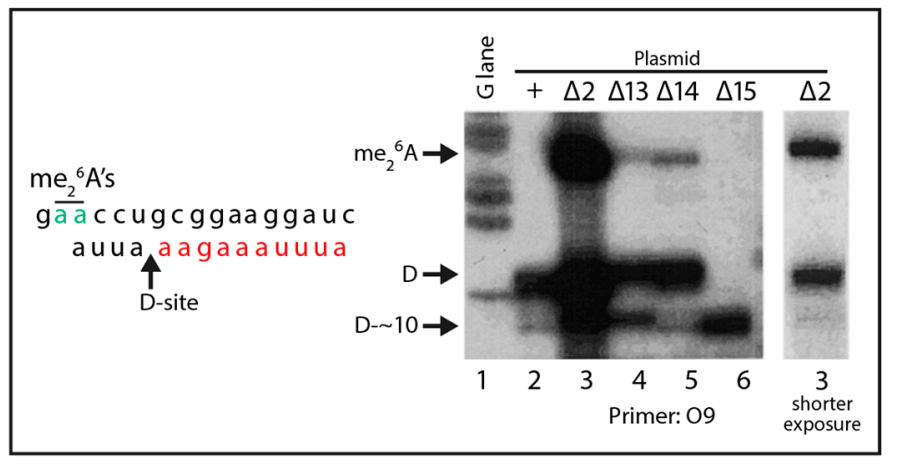

Figure 6. Mapping of $5^{\prime}$ ends at the D-site made by processing of pre-rRNA from wildtype and the indicated deletion mutants. Host $\Delta r p a 12$ carrying the indicated derivatives of pDK16-tag was grown at $25^{\circ}$ and shifted to $37^{\circ}$ for $6 \mathrm{~h}$. Total RNA was used for extension of primer O9 (Figure 1A). A G-lane made by dideoxy sequencing using pDK16 DNA and primer O9 is shown as markers. The blot on the right shows lane 3 from a shorter exposure of the blot in lanes 1-6. The nucleotide sequence around the D site is shown on the left to facilitate the interpretation of the G-lane as marker. Red: ITS1 nucleotides; black: 18S rRNA nucleotides; green: the dimethylated A residues.

There is an additional interesting result from the primer extension experiment: RNA from $\Delta 2$ (and, to a lesser extent, $\Delta 13$ and $\Delta 14$ ) generates a longer band whose length corresponds to the position of adenosines 1781-1782 near the end of 18S rRNA that are dimethylated in the mature rRNA [41] (Figure 6, lanes 3-5). This band is not visible with the wildtype RNA, presumably because the D-cleavage normally occurs at a faster rate, thereby preceding the A-methylation. We concludethat in the $\Delta 2, \Delta 13$, and $\Delta 14$ mutants, the $\mathrm{D}$ site cleavage is delayed relative to A-dimethylation, and that $3^{\prime}$ end maturation of $18 \mathrm{~S}$ rRNA is not a prerequisite for dimethylation. Similar results were seen previously in A2 site mutants [21,35]. 
To gain insight into the role of the $\mathrm{Xrn} 1$ exonuclease in the processing of the $\Delta 2$ prerRNA, we compared northern blots of RNA from $\triangle r p a 12$ with and without the XRN1 deletion, which stabilizes ITS1 processing fragments [38]. RNA was prepared from $\Delta r p a 12$ $\Delta x r n 1$ at 4 and $6 \mathrm{~h}$ after a shift from $25^{\circ}$ to $37^{\circ}$ and analyzed on northern blots of agarose and acrylamide gels probed with $\mathrm{O} 453$ (Figure 7A), which is complementary to nucleotides 15-25 of ITS1 (Figure 1A and Table 1). As previously observed [38], the elimination of Xrn1 activity with the wildtype ITS1 plasmid results in the accumulation of an RNA generated from cleavage at sites D and A2 (D-A2) (Figure 7A, lanes 1-2, and lanes 7-8). At $4 \mathrm{~h}$ post-temperature shift, the $\Delta 2$ mutant contained accumulated D-A2 RNA; we attribute that to residual but decreased transcription of the chromosomal rRNA genes by Pol I as it was undergoing inactivation after the temperature shift. However, the blot also revealed a longer fragment, labeled $\mathrm{X}$, derived from the processing of ITS1 from mutant $\triangle 2$ (Figure 7A, lanes 3-4 and lanes 9-10). By $6 \mathrm{~h}$, the D-A2 fragment was virtually gone, and only band $\mathrm{X}$ was visible (Figure 7A, lanes 5-6 and lanes 11-12). Furthermore, the wildtype 20S (pre-18S) band generated by cleavage at A2 (Figure 1; barely visible in Figure 7A, lanes 1-2) was replaced in the $\Delta 2$ mutant with a new " $24 \mathrm{~S}^{\prime}$ " slower moving band (Figure $7 \mathrm{~A}$, lanes 3-6). This RNA may be the same fragment we have previously observed in an RNase MRP mutant, which extends from the $5^{\prime}$ end of $18 \mathrm{~S}$ to the $3^{\prime}$ end (E site) of 5.8S rRNA [23,31]. Finally, several bands between $X$ and $20 S$ were observed after the temperature shift of $\Delta r p a 12 \Delta x r n 1 / \mathrm{pDK} \Delta 2$, indicating ectopic cleavage of $18 \mathrm{~S}$ rRNA (Figure $7 \mathrm{~A}$, compare lanes 3-6 with lanes 1-2).

Given the size of the $\Delta 2$ deletion, that $\Delta 2$ pre-rRNA is cleaved at the proper $\mathrm{D}$ site, that $\mathrm{O} 453$ hybridizes to ITS1 positions $15-25$, and the fact that band X is longer than D-A2, the $X$ fragment must have a $5^{\prime}$ end at or very close to the $D$ site and extend downstream of ITS1. We confirmed that $X$ includes $5.8 \mathrm{~S}$ by probing a blot of an acrylamide gel with the 5.8S-specific probe O20, which is complementary to the $3^{\prime} 25$ nucleotides of 5.8S. Probing with $\mathrm{O} 20$ of the blot of RNA from $\Delta r p a 12 \Delta x r n 1 / \mathrm{pDK} 16-\Delta 2$-tag revealed two fragments, one of which corresponds to $X$ (Figure 7B, lane 5). The other, called $X^{\prime}$, migrates slightly faster than $X$, but since it was not seen in the northern probed by O453, it must have a $5^{\prime}$ end downstream of the $\mathrm{D}$ site (Figure $7 \mathrm{~B}$, lane 5). Neither of the $X$ and $X^{\prime}$ bands hybridize to the $\mathrm{O} 90$ probe, complementary to the upstream part of ITS2 (Figure 7B, lane 11), suggesting that both $X$ and $X^{\prime}$ have $3^{\prime}$ ends at or close to the $3^{\prime}$ end of 5.8S rRNA (site E). Probing of

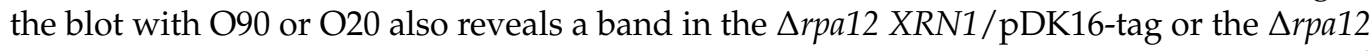
$X R N 1 / \mathrm{pDK} 16-\operatorname{tag} \Delta 2 \mathrm{RNA}$ corresponding to the 7S pre-rRNA (Figure 1A), which is the $3^{\prime}$ extended precursor for $5.8 \mathrm{~S}$ rRNA bracketed by the B1 and C2 sites (Figure 7B lanes 1-3 and 7-9). This band is also seen in $\Delta r p a 12 \Delta x r n 1 / p D K 16-t a g$ (Figure 7B, lanes 4 and 10). However, since the $7 \mathrm{~S}$ band is not seen in $\Delta r p a 12 \Delta x r n 1 / \mathrm{pDK} 16-\operatorname{tag} \Delta 2$ probed with O90, we concluded that, in the absence of $X \mathrm{rn} 1$ activity, the $3^{\prime}$ ends of $\mathrm{X}$ and $\mathrm{X}^{\prime}$ must be formed before the $5^{\prime}$ end of $5.8 \mathrm{~S}$ is processed (Figure 7B, lane 11). 


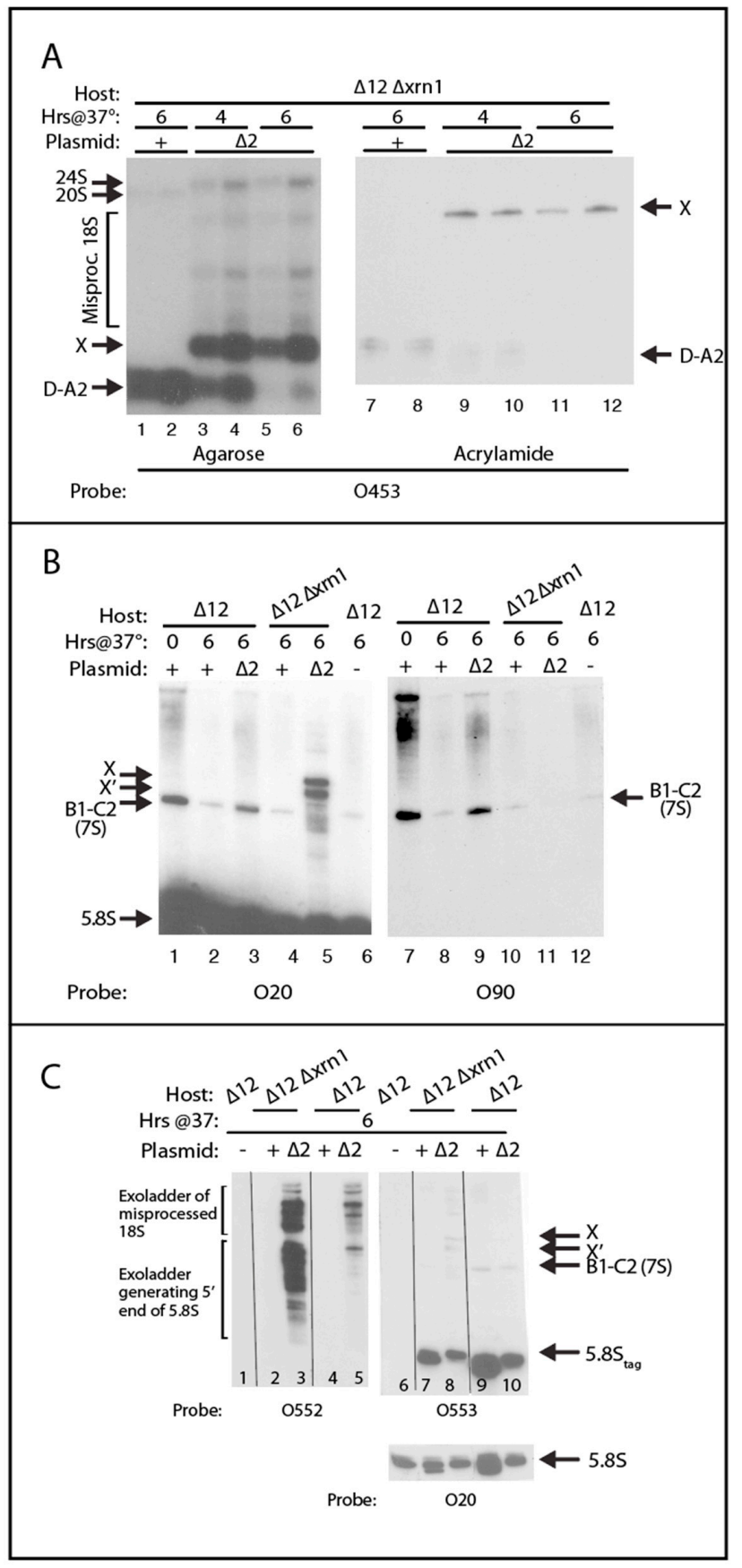

Figure 7. Characterization of intermediates in the processing of $\Delta 2$ pre-rRNA. Total RNA from $\Delta r p a 12$ XRN1 or $\Delta r p a 12 \Delta x r n 1$ carrying pDK16-tag with wildtype or $\Delta 2$ rRNA genes was extracted from cells grown at $25^{\circ}$ (time 0 ) or after cells were shifted to $37^{\circ}$ for 4 or $6 \mathrm{~h}$. The RNA was fractionated by agarose or acrylamide gel electrophoresis and analyzed by northern blots. (A) The wildtype D-A2 wildtype intermediate was replaced with a longer intermediate $(X)$ in $\Delta 2$ processing. Agarose (left) and acrylamide gels (right) were blotted and probed with $\mathrm{O} 453$. (B) The $\mathrm{X}$ and $\mathrm{X}^{\prime}$ intermediates in processing of $\Delta 2$ pre-rRNA include the $3^{\prime}$ end of $5.8 \mathrm{~S}$ rRNA. Acrylamide gels were blotted and probed with $\mathrm{O} 20$ or $\mathrm{O} 90$. (C) The $\Delta 2$ pre-rRNA processing intermediates were subject to exonuclease maturation. An acrylamide gel was blotted and probed with O552 (lanes 1-5), O553 (lanes 6-10), or O20 (5.8S slice of the blot showing the $5.8 \mathrm{~S}$ bands in lanes 6-10). All images in panel (C) came from the same blot, probed sequentially and stripped in between each probing; see text for details. The blots in this figure were not cropped at the top or the bottom of the blot, except for the O20 loading control at the bottom right of the figure. Irrelevant lanes were cut out in panel (C) (indicated by the lines). The specificity of the O552 probe is also evident from the uncropped blot in Figure S5. 
The probing of RNA from $\Delta r p a 12 \Delta x r n 1 / p D K 16-\operatorname{tag} \Delta 2$ with $\mathrm{O} 20$ also showed a series of bands below $X$ and $X^{\prime}$ (Figure 7B, lane 5), suggesting that the $X$ and $X^{\prime}$ RNA fragments are gradually shortened by exonuclease processing. To investigate this further, we designed a probe (O552) specific to RNA intermediates that included the $\Delta 2$ deletion (Figure $1 \mathrm{~A}$ ). This oligonucleotide is complementary to 9 nucleotides upstream and 11 nucleotides downstream of the $\Delta 2$ deletion in ITS1. Transcripts that encompass the $\Delta 2$ deletion can form a stable 20-basepair uninterrupted helix with the probe, while transcripts that do not contain the deletion are only able to form a 9- or 11-bp uninterrupted helix with O552, or a hybrid interrupted by a large loop, neither of which is stable enough to generate a hybrid under our hybridization conditions. As seen in Figure 7C, lanes 3 and 5, the O552 oligonucleotide only hybridizes to RNA from strains harboring pDK16-tag $\Delta 2$, confirming that O552 specifically reveals transcripts that span the $\Delta 2$ deletion. Moreover, RNA from both the $\Delta x r n 1$ and XRN1 strains containing $\mathrm{pDK} 16 \Delta 2$ form exonuclease degradation "ladders" with O552 (Figure 7C, lanes 3 and 5, respectively), but the intensity of ladders in RNA from $\Delta x r n 1$ are much greater (compare lane 3 with lane 5). The blot in Figure $7 \mathrm{C}$, lanes 1-5, was stripped and then hybridized consecutively with O553, specific to the Sp-tag (Figure 7C, lane 6-10), and finally with O20, which hybridizes to both tagged and untagged 5.8S rRNA (Figure 7C right bottom). The results show that there were similar amounts of tagged 5.8S rRNA in both samples (Figure 7C, lanes 8 and 10). Therefore, we ascribe the increased intensity in lane 3 relative to lane 5 to a slower degradation rate of ITS1 fragments when the Xrn1 endonuclease is absent, leading to a greater accumulation of the intermediates [42]. We conclude that $\mathrm{Xrn1}$ is the primary exonuclease generating the ladders and that, in the absence of the Xrn1 nuclease, the degradation is performed by another, slower $5^{\prime}>3^{\prime}$ exonuclease.

Comparison of lanes 3 and 5 with lane 8 in Figure $7 \mathrm{C}$ shows that the bands at the top of the lower cluster of exonuclease products have an electrophoretic mobility similar to the $X$ and $X^{\prime}$ bands, while the lower bands migrate almost as fast as $5.8 \mathrm{~S}_{\mathrm{L}}$. These results suggest that the lower ladders represent "trimming" of $X$ and $X^{\prime}$ RNA to form the mature $5^{\prime}$ end of 5.8S (Figure 7C, lanes 3 and 5). The upper ladder may represent trimming of RNA formed by misprocessing of $18 \mathrm{~S}$ rRNA.

\subsection{8S rRNA with $5^{\prime}$ Extended Ends Are Incorporated into Functional Ribosomes}

Since $\Delta 2$ rRNA supports growth at the non-permissive temperature of strain $\Delta r p a 12$, when the pDK16-tag $\Delta 2$ plasmid is the only source of rRNA, functional ribosomes must be formed from the pre-rRNA containing the $\Delta 2$ deletion (Figure S1A). We were curious to see if any of the $5^{\prime}$ extended 5.8S rRNA in $X, X^{\prime}$, and the exonuclease ladders are removed before or after the 5.8S rRNA is incorporated into ribosomes. Therefore, we fractionated by sucrose gradients whole-cell extracts of $\Delta r p a 12 \Delta x r n 1 / p D K 16-\operatorname{tag} \Delta 2$ (Figure 8). RNA extracted from each sucrose gradient fraction was analyzed on a northern blot probed with O576, which visualized the tagged 5.8S rRNA (Figure 8A). To locate the relevant ribosome peaks in the gradient, we quantified the relative amount of tagged 5.8S rRNA in each fraction (Figure $8 \mathrm{~B}$ ). The results demonstrate that the $5.8 \mathrm{~S}_{\mathrm{L}}$ processed from the $\Delta 2$ pre-rRNA is incorporated into $60 \mathrm{~S}$ and $80 \mathrm{~S}$ ribosomes as well as polysomes (Figure 8A, lanes 14-19 and lanes 21-27, respectively). Additionally, probing with O552 showed that the 5'-extended 5.8S RNA transcripts ("exoladders") were also incorporated into ribosomes, including polysomes (Figure 8A, lanes 42-55). In other words, the extensions did not preclude incorporation of the 5.8S-containing rRNA into functional ribosomes. The distribution of transcripts of different lengths in the exonuclease ladders was somewhat different in the transcripts extracted from ribosomes compared to the total RNA extracted in the presence of hot phenol (Figure 8A, lanes 29 and 56, see also Figure 7C, lanes 3 and 5), presumably because hot phenol used for RNA extraction from whole cells inactivates enzymatic activity immediately upon cell lysis, while some enzymatic activities, including exonucleases, may continue to operate in the crude lysates despite keeping the lysates on ice. Interestingly, " $24 S$ " rRNA containing the $\Delta 2$ mutant ITS1 is seen in complexes that 
sediment relatively slowly (Figure 8A, lanes $4-8$ ), but not in mature ribosomes. Thus, it appears that the " $24 \mathrm{~S}$ " transcript may be incorporated into slowly-sedimenting assembly intermediates (i.e., assembly intermediates in the early part of the assembly pathway) and that the $18 \mathrm{~S}$ part is separated from the ITS1-5.8S part before ribosomes become functional. Finally, we note that the L-fraction $\left(5.8 \mathrm{~S}_{\mathrm{L}} /\left(5.8 \mathrm{~S}_{\mathrm{L}}+5.8 \mathrm{~S}_{\mathrm{S}}\right)\right.$ is constant across the $60 \mathrm{~S}, 80 \mathrm{~S}$, and polysome peaks, showing that neither of the two $5.8 \mathrm{~S}$ forms are discriminated against in the $60 \mathrm{~S}$ assembly process.
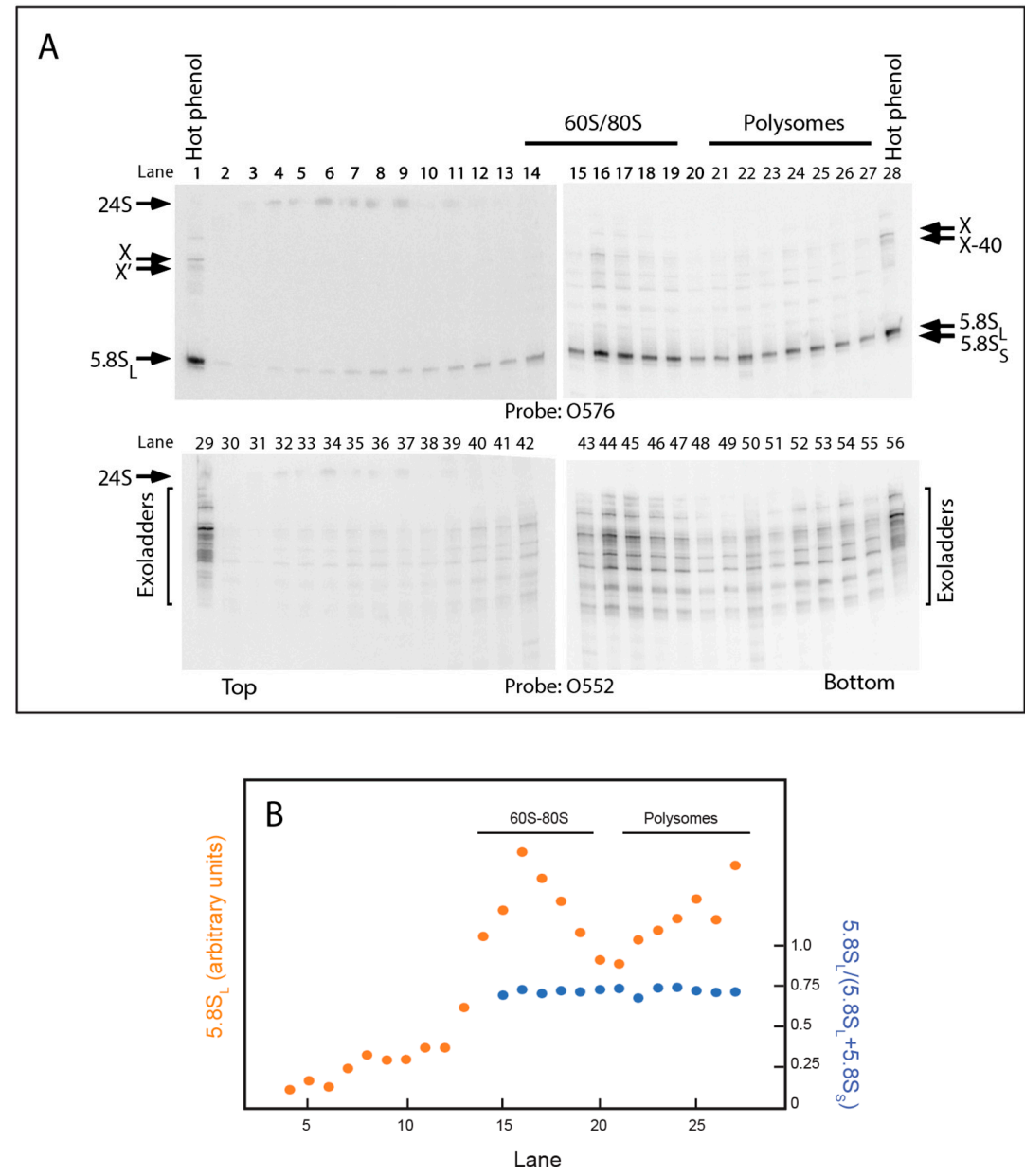

Figure 8. $5^{\prime}$ extended 5.8S rRNA is incorporated into 60S, $80 \mathrm{~S}$ and polysomal ribosomes. $\Delta r p a 12$ $\Delta x r n 1$ carrying pDK16-tag $\Delta 2$ rRNA genes was grown at $25^{\circ}$ and shifted to $37^{\circ}$ for $6 \mathrm{~h}$. Whole cell extracts were fractionated on sucrose gradients. RNA was then isolated from each fraction and subjected to acrylamide gel electrophoresis. Finally, RNA was transferred to nylon blots and probed with $\mathrm{O} 576$ or O552. (A) Northern blots. (B) Quantification of $5.8 \mathrm{~S}_{\mathrm{L}}$ (orange) and the L-fraction $\left(5.8 \mathrm{~S}_{\mathrm{L}} /\left(5.8 \mathrm{~S}_{\mathrm{L}}+5.8 \mathrm{~S}_{\mathrm{S}}\right)\right.$ across the gradient.

\section{Discussion}

\subsection{Steps in the Xrn1-Dependent Path to the $5^{\prime}$ End of $5.8 S_{L}$}

The canonical scheme for pre-rRNA processing includes pathways to generate two different $5^{\prime}$ ends, 7 nucleotides apart, of the $5.8 \mathrm{~S}$ rRNA (Figure 1A). The $5^{\prime}$ end of $5.8 \mathrm{~S}_{\mathrm{S}}$ (short $5.8 \mathrm{~S}$ ) is ostensibly created by cleavage at the A3 site in ITS1 by the endonuclease RNase MRP, followed by trimming by the exonucleases Rat1 and Rrp17 (Figures 1A and 2) [19-24]. The $5^{\prime}$ end of $5.8 \mathrm{~S}_{\mathrm{L}}$ (long 5.8S) is believed to be formed by an unknown endonuclease [25] (Figure 1A). However, a third pathway for $5.8 \mathrm{~S}$ processing was implied by our previous observation that formation of $5.8 \mathrm{~S}_{\mathrm{L}}$ requires exonuclease $\mathrm{Xrn} 1$ at non-permissive temperature in a temperature-sensitive RNase MRP mutant ("Mini2"). This mutation has a higher penetrance for RNase MRP inactivation than the rrp2-2 mutant used in Figures 3 and 5 [30]. 
In this report, we describe experiments that support the proposed Xrn1-dependent path to $5.8 \mathrm{~S}_{\mathrm{L}}$. By deleting most of the downstream-half of ITS1, including the A2 and A3 sites ( $\Delta 2$ mutant, Figure $2 \mathrm{~A}, \mathrm{~J})$, we blocked the two canonical processing pathways. This, in turn, uncovered a pathway, initiated by cleavage at the border between 18S and ITS1 (D site) followed by Xrn1 exonuclease trimming from $\mathrm{D}$ to the $\mathrm{B}_{\mathrm{L}} 5^{\prime}$ end (Figure 6, Figure 7 , and Figure 9A). The removal of ITS1 sequences by Xrn1 occurs, at least in part, after the $5^{\prime}$ end-extended $5.8 \mathrm{~S}$ rRNA is incorporated into functional $60 \mathrm{~S}$ subunits, as indicated by the presence of ITS1 sequences from $\Delta 2$ pre-rRNA in the 60S-80S-polysome region of sucrose gradients (Figure 8 ). This observation is consistent with previous studies showing that large ribosomal subunits in both bacteria and yeast can be functional even if the rRNA is incompletely processed $[43,44]$.

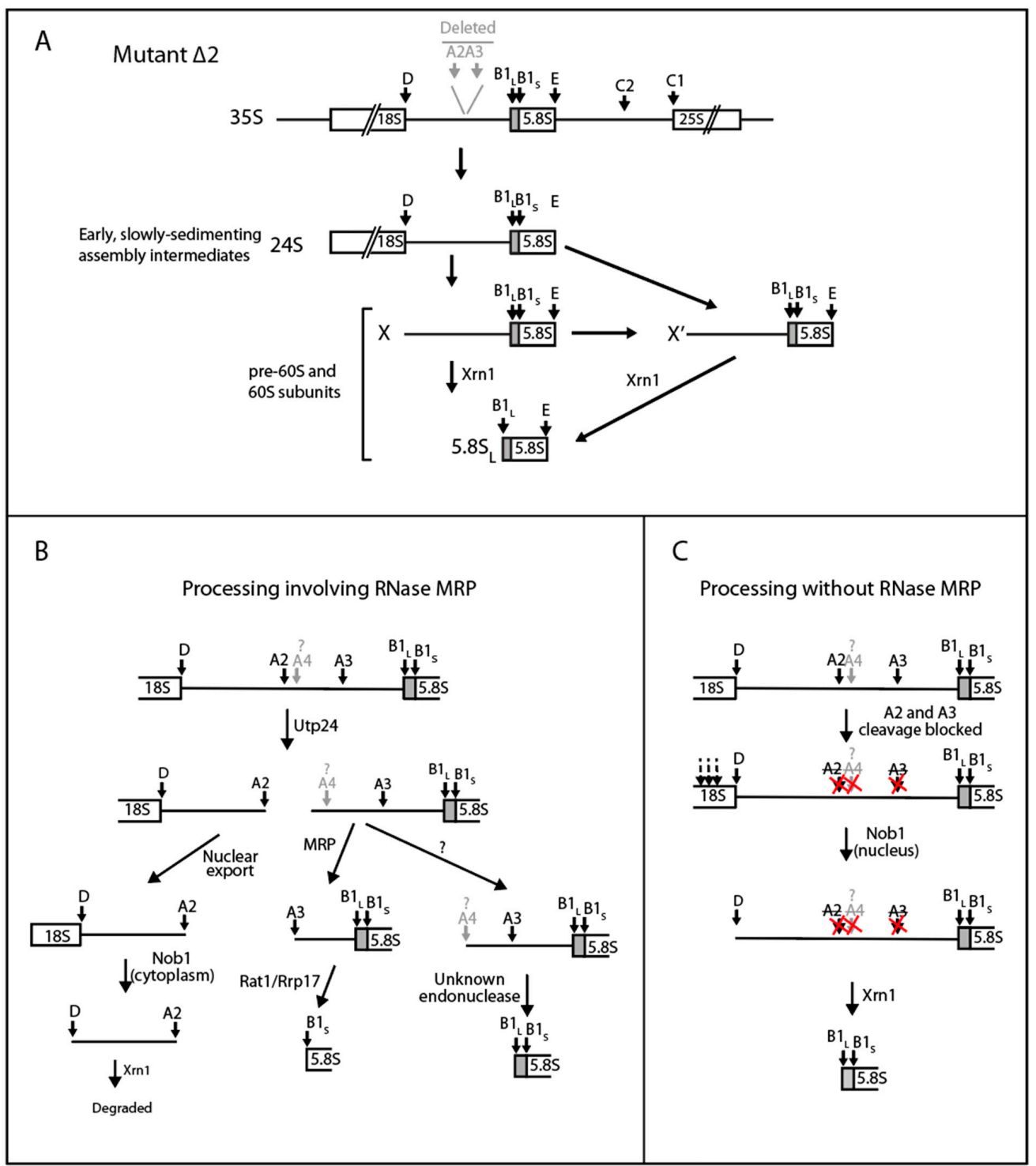

Figure 9. Models for ITS1 processing and switch between processing modes. (A) Xrn1-dependent processing of $\Delta 2$ prerRNA. See text for details. (B) Processing involving RNase MRP (canonical model). Note that the path to $5.8 \mathrm{~S}_{\mathrm{L}}$ involves an intermediate with a $5^{\prime}$ end (A4) a short distance downstream of A2 [25,45]. (C) Processing without RNase MRP participation. Inactivation of RNase MRP blocks cleavage at both $\mathrm{A} 2$ and $\mathrm{A} 3$, allowing Xrn1 exonuclease to degrade the entire region from $\mathrm{D}$ to $\mathrm{B} 1_{\mathrm{L}}$. We propose that the processing of pre-rRNA occurs via a competition between the pathways in panels $\mathrm{B}$ and $\mathrm{C}$, with the canonical model in panel B being dominant during growth under laboratory conditions. If RNase MRP activity is decreased due to change of growth conditions or mutations, the kinetic mix of the models in panels B and C switches in the direction of model C. In the extreme case of total inactivation of RNase MRP, processing occurs exclusively via the model in C. 
This new pathway shares two characteristics of the $5.8 \mathrm{~S}_{\mathrm{L}}$ formation from wildtype rRNA genes after temperature inactivation of RNase MRP in the rrp2-Mini2 mutant [30]. First, in neither case is ITS1 cleaved at either A2 or A3, and second, Xrn1 is implicated in both cases (see Figures 5 and 7 in [30]). These shared features suggest that, in the absence of RNase MRP activity, processing of wildtype pre-rRNA follows the pathway for $\Delta 2$ pre-rRNA processing. Moreover, northern analysis of RNA from the Mini2 mutant prior to RNase MRP temperature inactivation reveals an exonuclease ladder above $5.8 \mathrm{~S}_{\mathrm{L}}$ rRNA (see Figure 7 in [30]). This suggests that $\mathrm{Xrn} 1$ trimming is a normal pathway to $5.8 \mathrm{~S}_{\mathrm{L}}$ even in the presence of active RNase MRP. We concluded that the $5^{\prime}$ end of $5.8 \mathrm{~S}_{\mathrm{L}}$ can be formed either by Xrn1 or by an endonuclease while RNase MRP is active, but only the Xrn1-dependent pathway functions when RNase MRP is inactive (Figure 9B,C).

3.2. The RNase MRP-Induced Switch between $5.8 S_{L}$ and $5.8 S_{S}$ Production Not Due to Changes in A3 Cleavage

The canonical role of RNase MRP in $5.8 \mathrm{~S}_{\mathrm{S}}$ processing (Figure 1) is based on two observations. First, RNase MRP cleaves ITS1 rRNA at the A3 site in vitro $[18,46,47]$, and second, accumulation of $5.8 \mathrm{~S}_{\mathrm{S}}$ is decreased in RNase MRP mutants, ostensibly because of a decreased rate of RNase MRP cleavage at A3. If that were the case, no $5.8 \mathrm{~S}_{\mathrm{S}}$ should be made from pre-rRNA lacking the A3 site. However, processing from $\Delta 14$ and $\Delta 15$ pre-rRNAs yield normal amounts $5.8 \mathrm{~S}_{\mathrm{S}}$ even through these mutants lack the $\mathrm{A} 3$ site. In contrast, the $\Delta 17$ mutant that does have an A3 site yields more $5.8 \mathrm{~S}_{\mathrm{L}}$ than $5.8 \mathrm{~S}_{\mathrm{S}}$. Moreover, the balance between $5.8 \mathrm{~S}_{\mathrm{S}}$ and $5.8 \mathrm{~S}_{\mathrm{L}}$ production is lower in the $r r p 2-2$ mutant than in the $R R P 2$ wildtype sibling despite the lack of an A3 site (Figures 3 and 5). Together, these observations suggest that, in contrast to the canonical model, the RNase MRP-induced switch between production of $5.8 \mathrm{~S}_{\mathrm{S}}$ and $5.8 \mathrm{~S}_{\mathrm{L}}$ cannot depend on the rate of $\mathrm{A} 3$ cleavage. Rather, we suggest that RNase MRP mediates the switch between $5.8 \mathrm{~S}_{\mathrm{S}}$ and $5.8 \mathrm{~S}_{\mathrm{L}}$ by an indirect, rather than a direct, mechanism. The absence of A2 cleavage after inactivation of RNase MRP (Figure 5 in [30]) suggests that such a mechanism involves a blockade of A2 cleavage.

It should be noted that, even though 8 nucleotides around the $\mathrm{A} 3$ consensus sequence contact the RNase MRP binding pocket, only two nucleotides in the consensus sequence have a strong effect on the rate of cleavage [46-48]. Thus, we cannot exclude ectopic RNase MRP cleavage of $\Delta 14, \Delta 15$, and $\Delta 16$ in the $R R P 2$ strain, although if this were the case, we would have expected that such misplaced cleavage should also suppress the effect of the inhibition of $\mathrm{A} 3$ cleavage in the $\Delta 18$ mutant.

The RNA component of RNase MRP is essential for rRNA synthesis and growth in both yeast and humans $[30,49]$. However, the essential nature of RNase MRP RNA cannot be rationalized based on our understanding of its role in rRNA synthesis, since both $5.8 \mathrm{~S}_{\mathrm{S}}$ and $5.8 \mathrm{~S}_{\mathrm{L}}$ become incorporated into functional ribosomes (Figure 8 ). An investigation of the proposed alternate model for RNase MRP-dependent inactivation of A2 cleavage may shed some light of this matter

\subsection{The 3' End of ITS1 Facilitates the Xrn1-Mediated Processing}

The ITS1 mutants giving rise to preferential formation of $5.8 \mathrm{~S}_{\mathrm{L}}$ over $5.8 \mathrm{~S}_{\mathrm{S}}$ also accumulate high-molecular fragments in the $\triangle r p a 12 \triangle x r n 1$ mutant, but not in the RRP2 and $r r p 2-2$ strains, suggesting that the absence of Xrn1 causes a kinetic retardation of an early step in ITS1 processing (Table 3 and Figure S2). These mutants $(\Delta 2, \Delta 17, \Delta 18$, and $\Delta 19)$ also lack part or all of the distal ITS1 (nucleotides 290-340). The accumulation of the high-molecular weight fragments that the distal part of ITS1 facilitates the processing in the absence of Xrn1. We suggest that the distal ITS1 might facilitate folding of ITS1, or perhaps be the target for binding of rRNA processing factor(s). 


\subsection{The $3^{\prime}$ End Maturation of $18 S$ rRNA}

The $3^{\prime}$ end of $18 \mathrm{~S}$ rRNA is matured by Nob1 endonuclease cleavage at the D-site of the $20 \mathrm{~S}$ pre-rRNA [50]. The D-site cut is cut accurately in vivo $\Delta 2, \Delta 13$, and $\Delta 14$ (Figure 6) and in vitro in a substrate with just 24 nucleotides around the 18S-ITS1 border [40], indicating that the Bob1 target is defined locally. However, cleavage in $\Delta 15$, and partially in $\Delta 13$, at an alternate site shows that a region of ITS1 more than 200 nucleotides downstream of the D-site also influences the accuracy of Nob1 cleavage, perhaps due to loss or gain of specific secondary or tertiary structures of ITS1.

Nob1 binds, together with partner proteins Pno1 and Nop9, to both 18S and ITS1 sequences of the 20S pre-rRNA in the nuclear pre-40S particle; cleavage is then prevented until helicases remove the partner proteins [51-53]. The $\Delta 4$ and $\Delta 7$ deletions remove parts of the pre-rRNA binding sites for Nob1 and partner proteins, which may account for the negative effect on growth of those mutations.

Because the D-A2 fragment can be found in the cytoplasm [54,55], D cleavage is assumed to occur after export of $40 \mathrm{~S}$ ribosomal precursors particles from the nucleus to the cytoplasm. However, this does not exclude that D cleavage could also occur in the nucleus prior to export of the pre-40S, since Nob1 binds to pre-40S particles in the nucleus and its inhibitory proteins may conceivably be removed by nuclear helicases. Our results suggest that $\mathrm{D}$ cleavage does in fact occur in the nucleus. Since both known endonuclease targets within ITS1 (A2 and A3) have been deleted in $\Delta 2$, the recognized mechanism for separating the rRNA moieties destined for $40 \mathrm{~S}$ and $60 \mathrm{~S}$ ribosomes is blocked. Therefore, we propose that, in the $\Delta 2$ mutant, the rRNA for the two subunits is instead separated by D cleavage. However, since nuclear export of the large and small ribosomal subunits requires different export factors [56], it seems unlikely that $18 \mathrm{~S}$ and $5.8 \mathrm{~S} / 25 \mathrm{~S}$ would be exported together in a single pre-ribosome particle. Thus, we propose that $\mathrm{D}$-cleavage is a nuclear function during processing of $\Delta 2$ pre-rRNA. The cellular location of $\mathrm{D}$ cleavage may be determined by kinetic competition between nuclear export of pre- $40 S$ and cleavage at $D$. If the export is fast, Nob1 cleavage occurs predominantly in the cytoplasm, but during slow pre-40S export, Nob1 cleavage may become a nuclear function. In the case of $\Delta 2$ pre-rRNA processing, export of pre- $40 \mathrm{~S}$ is likely blocked until the precursors for $40 \mathrm{~S}$ and $60 \mathrm{~S}$ have been separated.

\subsection{Diversity of $r$ RNA Processing Pathways}

Like the pathway for bypass of ITS1 A2 and A3 cleavage described here, other steps for ribosome formation can also be bypassed by suppressor mutations. For example, Nsa1, a participant in restructuring one of the nucleolar pre-60S particles, requires the Rix7 ATPhelicase in order to be released from the pre-60S particle, but this step can be circumvented by mutations in EBP2 and MAK5 that eliminate the need for Nsa1 in facilitating pre-60S restructuring [57]. Similarly, a mutational change in the multifunctional protein Rrp5 can bypass A2 cleavage [58]. Moreover, mutations in Rsr1, Rpf2, or uL5, proteins that form a ribosomal subparticle with the $5 \mathrm{~S}$ rRNA before docking of $5 \mathrm{~S}$ rRNA-uL5 in the pre-60S particle, can suppress the need for Cgr1 in the final positioning of $5 \mathrm{~S}$ rRNA in the nascent pre-60S [59]. The theme for the bypass pathways may be that they co-exist in wildtype strains but are kinetically non-competitive. The suppressor mutations may change the kinetics of the bypass reaction relative to the canonical pathways, enabling these alternative pathways to become kinetically significant.

\section{Materials and Methods}

\subsection{Strains and Growth Conditions}

Yeast strains used are shown in Table 2. In $\Delta r p a 135$, the gene for the largest RNA polymerase subunit is disrupted, which inactivates RNA Pol I at all temperatures [33]. The pNOY102 plasmid in $\Delta r p a 135$ was replaced by pDK16 or pDK16 2 by transformation and selection for $\mathrm{TRP}^{+}$followed by counter-selection of pNOY102 (URA3) by growth on 5-fluoroorotic acid. 
In $\triangle$ rpa12, disruption of the gene for the smallest subunit of RNA-Pol I bestows temperature sensitivity for growth [34]. An XRN1 deletion derivative of the temperaturesensitive strain $\Delta r p a 12$ (called $\Delta r p a 12 \Delta x r n 1$ ) was constructed by transforming $\Delta r p a 12$ with a PCR fragment made from chromosomal DNA of an $x r n 1 \triangle B g 11:: U R A 3$ strain [60] and selecting for uracil prototrophy. Plasmids containing deletions within the long rRNA transcription unit were tested for their ability to support growth of transformants selected for tryptophan prototrophy. Transformants of $\Delta r p a 135$ were tested for growth on glucose medium in the presence and absence of $\mathrm{Cu}^{2+}$ at $30^{\circ}$. Transformants of $\Delta$ rpa12 were streaked on plates with or without $\mathrm{Cu}^{2+}$ and incubated at $25^{\circ}$ and $37^{\circ}$. Examples of these tests are shown in Figure S1. Plasmids pDK23 (carrying a 7-base deletion in the ITS1 A2 site) and pDK16 1 (lacking all DNA between ITS1 position 201 and 25S rRNA position 318) were used as positive and negative controls, respectively. Plasmids pDK16, pDK16 $\Delta 2$, and pDK23 supported growth of $\Delta$ rpa135 on glucose medium containing $\mathrm{Cu}^{2+}$ and growth of $\Delta$ rpa 12 at $37^{\circ}$ on glucose-Cu medium, while pDK16 containing the $\Delta 1, \Delta 4$, and $\Delta 5$ deletions do not. Growth of cells expressing only the $\Delta 2$ version of pre-rRNA shows that $\mathrm{pDK} 16 \Delta 2$ also supports ribosome formation. Similar tests of the remaining ITS1 deletion plasmids showed that pre-rRNA containing ITS1 deletions $\Delta 13, \Delta 14, \Delta 15, \Delta 16, \Delta 17, \Delta 18$, and $\Delta 19$ deletions also support growth (not shown).

Cultures of $\Delta r p a 135$ were grown in supplemented synthetic glucose medium lacking tryptophan and including $0.1 \mathrm{mM} \mathrm{Cu}^{2+}[61]$ at $30^{\circ}$, while $\Delta r p a 12$ and its $\Delta x r n 1$ derivative were grown in the same medium at $25^{\circ}$ in supplemented synthetic medium and shifted to $37^{\circ}$ for 4 or 6 hours as indicated.

\subsection{Plasmids and Oligonucleotides}

Plasmid pDK16 [35], a yeast-E.coli shuttle plasmid containing both 2-Micron and $\mathrm{ColEl}$ origins of replication, harbors a wildtype copy of the yeast rRNA transcription unit controlled by the CUP1 promoter. pNOY102 [33] carries a wildtype rRNA transcription unit expressed from the GAL7 promoter. Deletions were made in pDK16 by joining together PCR fragments with anchors of restriction enzyme recognition sites made with pNOY102 as template.

Oligonucleotides used for northern and primer extension analyses are listed in Table 1. Two probes (O553 and O576) were made for the Sp-tag on pDK16. Both work for northern analysis, but $\mathrm{O} 553$ has a propensity for hairpin formation that appears to limit its capacity to work in primer extension.

\subsection{Other Procedures}

Total RNA for gel electrophoresis was extracted from $0.3 \mathrm{~mL}$ of culture $\left(\sim 10^{7}\right.$ cells per $\mathrm{ml})$ by mixing with buffer containing hot $\left(\sim 90^{\circ} \mathrm{C}\right)$ phenol in TSE1 $(0.02 \mathrm{M}$ of Tris- $\mathrm{HCl}, \mathrm{pH}$ $7.4 ; 0.2 \mathrm{M}$ of NaCl; $0.04 \mathrm{M}$ of Na-EDTA; $0.1 \%$ sodium dodecylsulfate) and immediately vortexed with glass beads followed by extraction with phenol- $\mathrm{CHCl}_{3}$-isoamyl alcohol (25:24:1) and then with $\mathrm{CHCl}_{3}$-isoamyl alcohol (24:1) [31]. Agarose gel electrophoresis was done on $1 \%$ agarose in TBE (90 mM Tris-borate, $\mathrm{pH} 8.3$, and $2 \mathrm{mM}$ EDTA-Na). Each lane was loaded with $3 \mu \mathrm{g}$ total RNA (0.06 A260 units). Acrylamide gel electrophoresis was done on $8 \%$ gels in $0.5 \times$ TBE. Each lane was loaded with $5 \mu \mathrm{g}$ of total RNA. RNA was transferred to nylon membranes by capillary blotting for agarose gels and electro-transfer for acrylamide gels. RNA was crosslinked to the membrane by UV irradiation and hybridized with ${ }^{32} \mathrm{P}-$ end-labeled oligonucleotides, followed by exposing the blot to storage phosphorimager screens. Autoradiograms were scanned on an 860 Storm imager (Molecular Dynamics). Bands on the images were quantified using Adobe Photoshop version 22.4.1. Graphing and statistical analysis were done with Microsoft Excel for the Mac version 16.49. Whole cell extracts for sucrose gradient analysis were prepared from quick-chilled cells by vortexing with glass beads in gradient buffer ( $50 \mathrm{mM}$ of Tris-acetate, $\mathrm{pH} 7,50 \mathrm{mM}$ of $\mathrm{NH}_{4} \mathrm{Cl}, 12 \mathrm{mM}$ of $\mathrm{MgCl}_{2}$, and $1 \mathrm{mM}$ of DTT) containing $50 \mu \mathrm{g}$ cycloheximide per ml. Sucrose gradients $(10-50 \%)$ were loaded with 20 A260 units and centrifuged at $40,000 \mathrm{rpm}$ for $6 \mathrm{~h}$ at $4{ }^{\circ} \mathrm{C}$ 
using an SW40Ti Beckman rotor. Finally, fractions (500 $\mu \mathrm{L})$ were collected [62]. Primer extension was performed by hybridizing with ${ }^{32} \mathrm{P}$-end-labeled $\mathrm{O} 9$ oligonucleotide followed by incubation with reverse transcriptase [63].

Supplementary Materials: The following are available online at https:/ /www.mdpi.com/article/10 $.3390 /$ ijms22136690/s1.

Author Contributions: Conceptualization, L.L.; methodology, X.L., J.M.Z. and L.L.; data curation, X.L. and L.L.; formal analysis, X.L., J.M.Z. and L.L.; validation J.M.Z. and L.L.; resources, L.L. and J.M.Z.; original draft preparation, L.L.; editing review and editing, J.M.Z. and L.L. All authors have read and agreed to the published version of the manuscript.

Funding: This work was funded by grant 54876 from the National Institute for General Medical Science.

Institutional Review Board Statement: Not applicable.

Informed Consent Statement: Not applicable.

Data Availability Statement: Not applicable.

Acknowledgments: We thank Susan Fretz for superb technical assistance.

Conflicts of Interest: The authors declare no conflict of interest.

\section{References}

1. Maaløe, O.; Kjeldgaard, N.O. Control of Macromolecular Synthesis; Benjamin: New York, NY, USA, 1966.

2. Kjeldgaard, N.O.; Maaloe, O.; Schaechter, M. The transition between different physiological states during balanced growth of Salmonella typhimurium. J. Gen. Microbiol. 1958, 19, 607-616. [CrossRef]

3. Warner, J.R. The economics of ribosome biosynthesis in yeast. Trends. Biochem. Sci. 1999, 24, 437-440. [CrossRef]

4. Cerezo, E.; Plisson-Chastang, C.; Henras, A.K.; Lebaron, S.; Gleizes, P.E.; O’Donohue, M.F.; Romeo, Y.; Henry, Y. Maturation of pre-40S particles in yeast and humans. Wiley. Interdiscip. Rev. RNA 2019, 10, e1516. [CrossRef] [PubMed]

5. Tomecki, R.; Sikorski, P.J.; Zakrzewska-Placzek, M. Comparison of preribosomal RNA processing pathways in yeast, plant and human cells-Focus on coordinated action of endo- and exoribonucleases. FEBS Lett. 2017, 591, 1801-1850. [CrossRef]

6. Bohnsack, K.E.; Bohnsack, M.T. Uncovering the assembly pathway of human ribosomes and its emerging links to disease. $E M B O$ J. 2019, 38, e100278. [CrossRef] [PubMed]

7. Klinge, S.; Woolford, J.L., Jr. Ribosome assembly coming into focus. Nat. Rev. Mol. Cell Biol. 2019, 20, 116-131. [CrossRef]

8. Bassler, J.; Hurt, E. Eukaryotic Ribosome Assembly. Annu. Rev. Biochem. 2019, 88, 8.1-8.26. [CrossRef]

9. Woolford, J.L., Jr.; Baserga, S.J. Ribosome biogenesis in the yeast Saccharomyces cerevisiae. Genetics 2013, 195, 643-681. [CrossRef] [PubMed]

10. Axt, K.; French, S.L.; Beyer, A.L.; Tollervey, D. Kinetic analysis demonstrates a requirement for the Rat1 exonuclease in cotranscriptional pre-rRNA cleavage. PLoS ONE 2014, 9, e85703. [CrossRef]

11. Talkish, J.; Biedka, S.; Jakovljevic, J.; Zhang, J.; Tang, L.; Strahler, J.R.; Andrews, P.C.; Maddock, J.R.; Woolford, J.L., Jr. Disruption of ribosome assembly in yeast blocks cotranscriptional pre-rRNA processing and affects the global hierarchy of ribosome biogenesis. RNA 2016, 22, 852-866. [CrossRef] [PubMed]

12. An, W.; Du, Y.; Ye, K. Structural and functional analysis of Utp24, an endonuclease for processing 18S ribosomal RNA. PLoS ONE 2018, 13, e0195723. [CrossRef] [PubMed]

13. Kufel, J.; Dichtl, B.; Tollervey, D. Yeast Rnt1p is required for cleavage of the pre-ribosomal RNA in the $3^{\prime}$ ETS but not the $5^{\prime}$ ETS. RNA 1999, 5, 909-917. [CrossRef] [PubMed]

14. Bleichert, F.; Granneman, S.; Osheim, Y.N.; Beyer, A.L.; Baserga, S.J. The PINc domain protein Utp24, a putative nuclease, is required for the early cleavage steps in $18 \mathrm{~S}$ rRNA maturation. Proc. Natl. Acad. Sci. USA 2006, 103, 9464-9469. [CrossRef] [PubMed]

15. Wells, G.R.; Weichmann, F.; Colvin, D.; Sloan, K.E.; Kudla, G.; Tollervey, D.; Watkins, N.J.; Schneider, C. The PIN domain endonuclease Utp24 cleaves pre-ribosomal RNA at two coupled sites in yeast and humans. Nucleic Acids Res. 2016, $44,9016$. [CrossRef]

16. Mitchell, P.; Petfalski, E.; Shevchenko, A.; Mann, M.; Tollervey, D. The exosome: A conserved eukaryotic RNA processing complex containing multiple $3^{\prime} \rightarrow 5^{\prime}$ exoribonucleases. Cell 1997, 91, 457-466. [CrossRef]

17. Geerlings, T.H.; Vos, J.C.; Raue, H.A. The final step in the formation of $25 \mathrm{~S}$ rRNA in Saccharomyces cerevisiae is performed by $5^{\prime} \rightarrow 3^{\prime}$ exonucleases. RNA 2000, 6, 1698-1703. [CrossRef]

18. Lygerou, Z.; Allmang, C.; Tollervey, D.; Seraphin, B. Accurate processing of a eukaryotic precursor ribosomal RNA by ribonuclease MRP in vitro. Science 1996, 272, 268-270. [CrossRef] 
19. Henry, Y.; Wood, H.; Morrissey, J.P.; Petfalski, E.; Kearsey, S.; Tollervey, D. The $5^{\prime}$ end of yeast $5.8 \mathrm{~S}$ rRNA is generated by exonucleases from an upstream cleavage site. EMBO J. 1994, 13, 2452-2463. [CrossRef] [PubMed]

20. Oeffinger, M.; Zenklusen, D.; Ferguson, A.; Wei, K.E.; El Hage, A.; Tollervey, D.; Chait, B.T.; Singer, R.H.; Rout, M.P. Rrp17p is a eukaryotic exonuclease required for $5^{\prime}$ end processing of Pre-60S ribosomal RNA. Mol. Cell 2009, 36, 768-781. [CrossRef]

21. Allmang, C.; Henry, Y.; Morrissey, J.P.; Wood, H.; Petfalski, E.; Tollervey, D. Processing of the yeast pre-rRNA at sites A and A is linked. RNA 1996, 2, 63-73.

22. Schmitt, M.E.; Clayton, D.A. Nuclear RNase MRP is required for correct processing of pre-5.8S rRNA in Saccharomyces. cerevisiae. Mol. Cell Biol. 1993, 13, 7935-7941. [PubMed]

23. Chu, S.; Archer, R.H.; Zengel, J.M.; Lindahl, L. The RNA of RNase MRP is required for normal processing of ribosomal RNA. Proc. Natl. Acad. Sci. USA 1994, 91, 659-663. [CrossRef] [PubMed]

24. Granneman, S.; Petfalski, E.; Tollervey, D. A cluster of ribosome synthesis factors regulate pre-rRNA folding and 5.8S rRNA maturation by the Rat1 exonuclease. EMBO J. 2011. [CrossRef]

25. Faber, A.W.; Vos, H.R.; Vos, J.C.; Raue, H.A. $5^{\prime}$-end formation of yeast 5.8SL rRNA is an endonucleolytic event. Biochem. Biophys. Res. Commun. 2006, 345, 796-802. [CrossRef]

26. Shadel, G.S.; Buckenmeyer, G.A.; Clayton, D.A.; Schmitt, M.E. Mutational analysis of the RNA component of Saccharomyces cerevisiae RNase MRP reveals distinct nuclear phenotypes. Gene 2000, 245, 175-184. [CrossRef]

27. Cai, T.; Reilly, T.R.; Cerio, M.; Schmitt, M.E. Mutagenesis of SNM1, which encodes a protein component of the yeast RNase MRP, reveals a role for this ribonucleoprotein endoribonuclease in plasmid segregation. Mol. Cell Biol. 1999, 19, 7857-7869. [CrossRef]

28. Chu, S.; Zengel, J.M.; Lindahl, L. A novel protein shared by RNase MRP and RNase, P. RNA 1997, 3, 382-391.

29. Lygerou, Z.; Mitchell, P.; Petfalski, E.; Seraphin, B.; Tollervey, D. The POP1 gene encodes a protein component common to the RNase MRP and RNase P ribonucleoproteins. Genes Dev. 1994, 8, 1423-1433. [CrossRef] [PubMed]

30. Lindahl, L.; Bommankanti, A.; Li, X.; Hayden, L.; Jones, A.; Khan, M.; Oni, T.; Zengel, J.M. RNase MRP is required for entry of $35 \mathrm{~S}$ precursor rRNA into the canonical processing pathway. RNA 2009, 15, 1407-1416. [CrossRef]

31. Lindahl, L.; Archer, R.H.; Zengel, J.M. A new rRNA processing mutant of Saccharomyces cerevisiae. Nucleic Acids Res. 1992, 20, 295-301. [CrossRef]

32. Schweizer, E.; MacKechnie, C.; Halvorson, H.O. The redundancy of ribosomal and transfer RNA genes in Saccharomyces cerevisiae. J. Mol. Biol. 1969, 40, 261-277. [CrossRef]

33. Nogi, Y.; Yano, R.; Nomura, M. Synthesis of large rRNAs by RNA polymerase II in mutants of Saccharomyces. cerevisiae. defective in RNA polymerase I. Proc. Natl. Acad. Sci. USA 1991, 88, 3962-3966. [CrossRef] [PubMed]

34. Nogi, Y.; Yano, R.; Dodd, J.; Carles, C.; Nomura, M. Gene RRN4 in Saccharomyces. cerevisiae. encodes the A12.2 subunit of RNA polymerase I and is essential only at high temperatures. Mol. Cell. Biol. 1993, 13, 114-122. [CrossRef] [PubMed]

35. Lindahl, L.; Archer, R.H.; Zengel, J.M. Alternate pathways for processing in the internal transcribed spacer 1 in pre-rRNA of Saccharomyces. cerevisiae. Nucleic. Acids. Res. 1994, 22, 5399-5407. [CrossRef]

36. Stevens, A.; Hsu, C.L.; Isham, K.R.; Larimer, F.W. Fragments of the internal transcribed spacer 1 of pre-rRNA accumulate in Saccharomyces. cerevisiae. lacking 5'-3' exoribonuclease 1. J. Bacteriol. 1991, 173, 7024-7028. [CrossRef]

37. Rubin, G.M. The nucleotide sequence of Saccharomyces. cerevisiae. 5.8 S ribosomal ribonucleic acid. J. Biol. Chem. 1973, 248, 3860-3875. [CrossRef]

38. van Nues, R.W.; Rientjes, J.M.; van der Sande, C.A.; Zerp, S.F.; Sluiter, C.; Venema, J.; Planta, R.J.; Raue, H.A. Separate structural elements within internal transcribed spacer 1 of Saccharomyces cerevisiae precursor ribosomal RNA direct the formation of $17 \mathrm{~S}$ and 26S rRNA. Nucleic Acids Res. 1994, 22, 912-919. [CrossRef]

39. Li, X.; Zaman, S.; Langdon, Y.; Zengel, J.M.; Lindahl, L. Identification of a functional core in the RNA component of RNase MRP of budding yeasts. Nucleic Acids Res. 2004, 32, 3703-3711. [CrossRef]

40. Pertschy, B.; Schneider, C.; Gnadig, M.; Schafer, T.; Tollervey, D.; Hurt, E. RNA helicase Prp43 and its co-factor Pfa1 promote 20 to $18 \mathrm{~S}$ rRNA processing catalyzed by the endonuclease Nob1. J. Biol. Chem. 2009, 284, 35079-35091. [CrossRef] [PubMed]

41. Lafontaine, D.; Delcour, J.; Glasser, A.L.; Desgres, J.; Vandenhaute, J. The DIM1 gene responsible for the conserved m6Am6A dimethylation in the $3^{\prime}$-terminal loop of $18 \mathrm{~S}$ rRNA is essential in yeast. J. Mol. Biol. 1994, 241, 492-497. [CrossRef] [PubMed]

42. Lindahl, L. Intermediates and time kinetics of the in vivo assembly of Escherichia coli ribosomes. J. Mol. Biol. 1975, 92, 15-37. [CrossRef]

43. Lawrence, M.G.; Shamsuzzaman, M.; Kondopaka, M.; Pascual, C.; Zengel, J.M.; Lindahl, L. The extended loops of ribosomal proteins uL4 and uL22 of Escherichia coli contribute to ribosome assembly and protein translation. Nucleic Acids Res. 2016, 44, 5798-5810. [CrossRef] [PubMed]

44. Rodriguez-Galan, O.; Garcia-Gomez, J.J.; Kressler, D.; de la Cruz, J. Immature large ribosomal subunits containing the 7S pre-rRNA can engage in translation in Saccharomyces cerevisiae. RNA Biol. 2015, 12, 838-846. [CrossRef] [PubMed]

45. Vos, H.R.; Faber, A.W.; de Gier, M.D.; Vos, J.C.; Raue, H.A. Deletion of the three distal S1 motifs of Saccharomyces cerevisiae Rrp5p abolishes pre-rRNA processing at site A without reducing the production of functional 40S subunits. Eukaryot. Cell. 2004, 3, 1504-1512. [CrossRef] [PubMed]

46. Esakova, O.; Perederina, A.; Quan, C.; Berezin, I.; Krasilnikov, A.S. Substrate recognition by ribonucleoprotein ribonuclease MRP. RNA 2011, 17, 356-364. [CrossRef] 
47. Lan, P.; Zhou, B.; Tan, M.; Li, S.; Cao, M.; Wu, J.; Lei, M. Structural insight into precursor ribosomal RNA processing by ribonuclease MRP. Science 2020, 369, 656-663. [CrossRef]

48. Perederina, A.; Li, D.; Lee, H.; Bator, C.; Berezin, I.; Hafenstein, S.L.; Krasilnikov, A.S. Cryo-EM structure of catalytic ribonucleoprotein complex RNase MRP. Nat. Commun. 2020, 11, 3474. [CrossRef]

49. Goldfarb, K.C.; Cech, T.R. Targeted CRISPR disruption reveals a role for RNase MRP RNA in human preribosomal RNA processing. Genes Dev. 2017, 31, 59-71. [CrossRef]

50. Fatica, A.; Oeffinger, M.; Dlakic, M.; Tollervey, D. Nob1p is required for cleavage of the $3^{\prime}$ end of $18 \mathrm{~S}$ rRNA. Mol. Cell. Biol. 2003, 23, 1798-1807. [CrossRef]

51. Ameismeier, M.; Zemp, I.; van den Heuvel, J.; Thoms, M.; Berninghausen, O.; Kutay, U.; Beckmann, R. Structural basis for the final steps of human $40 \mathrm{~S}$ ribosome maturation. Nature 2020, 587, 683-687. [CrossRef]

52. Turowski, T.W.; Lebaron, S.; Zhang, E.; Peil, L.; Dudnakova, T.; Petfalski, E.; Granneman, S.; Rappsilber, J.; Tollervey, D. Rio1 mediates ATP-dependent final maturation of $40 S$ ribosomal subunits. Nucleic Acids Res. 2014, 42, 12189-12199. [CrossRef]

53. Zhang, J.; McCann, K.L.; Qiu, C.; Gonzalez, L.E.; Baserga, S.J.; Hall, T.M. Nop9 is a PUF-like protein that prevents premature cleavage to correctly process pre-18S rRNA. Nat. Commun. 2016, 7, 13085. [CrossRef] [PubMed]

54. Udem, S.A.; Warner, J.R. The cytoplasmic maturation of a ribosomal precursor ribonucleic acid in yeast. J. Biol. Chem. 1973, 248, 1412-1416. [CrossRef]

55. Moy, T.I.; Silver, P.A. Nuclear export of the small ribosomal subunit requires the ran-GTPase cycle and certain nucleoporins [In Process Citation]. Genes Dev. 1999, 13, 2118-2133. [CrossRef]

56. Pena, C.; Hurt, E.; Panse, V.G. Eukaryotic ribosome assembly, transport and quality control. Nat. Struct. Mol. Biol. 2017, 24, 689-699. [CrossRef] [PubMed]

57. Pratte, D.; Singh, U.; Murat, G.; Kressler, D. Mak5 and Ebp2 act together on early pre-60S particles and their reduced functionality bypasses the requirement for the essential pre-60S factor Nsa1. PLoS ONE 2013, 8, e82741. [CrossRef]

58. Torchet, C.; Hermann-Le Denmat, S. Bypassing the rRNA processing endonucleolytic cleavage at site A2 in Saccharomyces cerevisiae. RNA 2000, 6, 1498-1508. [CrossRef]

59. Thoms, M.; Mitterer, V.; Kater, L.; Falquet, L.; Beckmann, R.; Kressler, D.; Hurt, E. Suppressor mutations in Rpf2-Rrs1 or Rp15 bypass the Cgr1 function for pre-ribosomal 5S RNP-rotation. Nat. Commun. 2018, 9, 4094. [CrossRef] [PubMed]

60. Larimer, F.W.; Stevens, A. Disruption of the gene XRN1, coding for a $5^{\prime} \rightarrow 3^{\prime}$ exoribonuclease, restricts yeast cell growth. Gene 1990, 95, 85-90. [CrossRef]

61. Sherman, F.; Lawrence, C.W.; Fink, G.R. Methods in Yeast Genetics; Cold Spring Harbor Laboratory: Cold Spring Harbor, NY, USA, $1979 ;$ p. 98.

62. Gregory, B.; Rahman, N.; Bommakanti, A.; Shamsuzzaman, M.; Thapa, M.; Lescure, A.; Zengel, J.M.; Lindahl, L. The small and large ribosomal subunits depend on each other for stability and accumulation. Life. Sci. Alliance 2019, 2. [CrossRef]

63. McCormick, J.R.; Zengel, J.M.; Lindahl, L. Intermediates in the degradation of mRNA from the lactose operon of Escherichia coli. Nucleic Acids Res. 1991, 19, 2767-2776. [CrossRef] [PubMed] 